\title{
Determinação de chumbo em açúcar por espectrometria de absorção atômica em forno de grafite tratado com tungstênio e ródio
}

\section{PAULINO FLORÊNCIO DE SOUZA}

Dissertação apresentada ao Centro de Energia Nuclear na Agricultura, da Universidade de São Paulo, como parte dos requisitos para a obtenção do título de Mestre em Ciências. Área de Concentração Energia Nuclear na Agricultura.

\author{
PIRACICABA \\ Estado de São Paulo - Brasil \\ Dezembro - 2004
}




\title{
Determinação de chumbo em açúcar por espectrometria de absorção atômica em forno de grafite tratado com tungstênio e ródio
}

\section{PAULINO FLORÊNCIO DE SOUZA Químico}

\author{
Orientador: Prof. Dr. FRANCISCO JOSÉ KRUG
}

Dissertação apresentada ao Centro de Energia Nuclear na Agricultura, da Universidade de São Paulo, como parte dos requisitos para a obtenção do título de Mestre em Ciências. Área de Concentração Energia Nuclear na Agricultura.

PIRACICABA

Estado de São Paulo - Brasil

Dezembro - 2004 
Dados Internacionais de Catalogação na Publicação (CIP) Seção Técnica de Biblioteca - CENA/USP

Souza, Paulino Florêncio de

Determinação de chumbo em açúcar por espectrometria de absorção atômica em forno de grafite tratado com tungstênio e ródio / Paulino Florêncio de Souza. - - Piracicaba, 2004.

67p. : il.

Dissertação (mestrado) - - Centro de Energia Nuclear na Agricultura, 2004.

1. Atomização eletrotérmica 2. Atomizador de grafite 3. Modificador químico 4. Química analítica quantitativa I. Título

CDU 543.42 
À Deus,

À minha esposa Izabel Christina pelo apoio e compreensão,

Aos meus filhos Rafael e Isabela,

Aos meus pais,

Aos meus irmãos

Com carinho dedico 
AGRADECIMENTOS

Ao Prof. Dr. Francisco José Krug, pela amizade, orientação, e incentivo.

Ao Prof. Dr. José Anchieta Gomes Neto do Instituto de Química da Universidade Estadual Paulista - UNESP, Campus de Araraquara.

Aos pesquisadores do Laboratório da Química Analítica "Prof. Henrique Bergamin Filho" do Centro de Energia Nuclear na Agricultura (CENA-USP).

Aos amigos do Grupo da Química Analítica: Tatinha, Poliana, Andréa, Paulo, Otávio, Quienly, Flávio, Fernando, Samuel. Em especial ao Dário, pelas contribuições na realização deste trabalho.

A Adriana P. de Oliveira do Instituto de Química da Universidade Estadual Paulista - UNESP, Campus de Araraquara.

Ao Centro de Tecnologia Copersucar.

Ao Centro de Energia Nuclear na Agricultura (CENA-USP).

As bibliotecárias do CENA: Raquel e Renata pela colaboração.

Ao secretário José V. Souto (Zezinho), pelos serviços prestados.

A todas as pessoas que de forma direta ou indireta contribuíram para a realização deste trabalho.

Ao CNPq, pelo auxílio e financiamento de parte do projeto (Processos: 478871/2003-1 e 306352/2003-6). 


\section{SUMÁRIO}

Página

LISTA DE FIGURAS ....................................................... vii

LISTA DE TABELAS ........................................................ $\mathrm{x}$

LISTA DE ABREVIAÇÕES................................................. xii

RESUMO

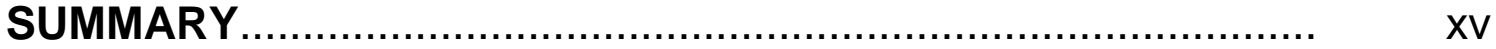

1. INTRODUÇÃO

2. REVISÃO DE LITERATURA .............................................. 4

2.1 Modificadores na espectrometria de absorção atômica com 13 forno de grafite GFAAS)

3. MATERIAL E MÉTODOS.

3.1 Descontaminação dos materiais e armazenagem das

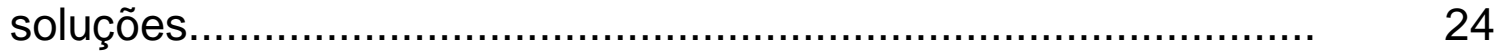

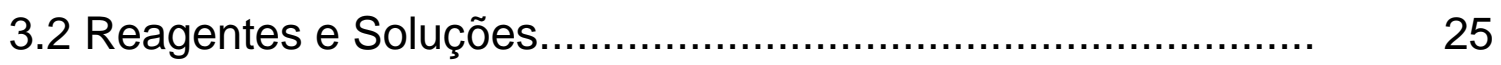

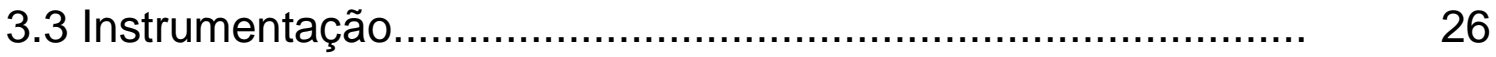

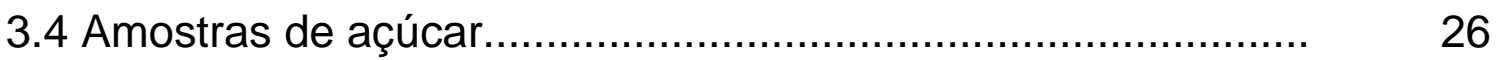

3.5 Preparação das amostras de açúcar...................................... 27

3.6 Revestimento da superfície grafitica..................................... 27

Revestimento com tungstênio............................................... 27

Revestimento com ródio........................................................... 28

4. PROCEDIMENTO EXPERIMENTAL ..................................... 29

4.1 Curva de temperatura de pirólise......................................... 29

4.2 Curva de temperatura de atomização..................................... 30

4.3 Limites de detecção............................................................ 31 
5. RESULTADOS E DISCUSSÃO.

5.1 Programas de aquecimento para determinação de chumbo

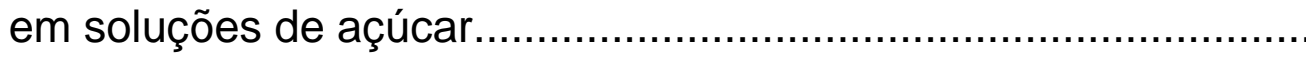

5.2 Tempo de vida útil do tubo de grafite.................................... 42

5.3 Características analíticas................................... $\quad 45$

5.4 Comparação do método proposto para determinação direta de chumbo em açúcar............................................................... 49

6. CONCLUSÕES ................................................................. 51

REFERÊNCIAS BIBLIOGRÁFICAS ..................................... 52 


\section{LISTA DE FIGURAS}

Página

Figura 1 Métodos de preparo de amostras de açúcar avaliados por Leblebici \& Volkan (1998).

Figura 2 Curvas de temperatura de pirólise $\left(T_{\text {atomização }}=1800^{\circ} \mathrm{C}\right)$ para 10 $\mu \mathrm{l}$ de solução $50 \mu \mathrm{g} \mathrm{I}^{-1} \mathrm{~Pb}$ em solução $8 \% \mathrm{~m} / \mathrm{v}$ açúcar em $0,2 \%$ v/v $\mathrm{HNO}_{3}$. Plataforma revestida com $250 \mu \mathrm{g} \mathrm{W}+200 \mu \mathrm{gh}$. (•) Sem injeção de Rh. (অ) Com Injeção de $5 \mu \mathrm{gh}$. (4) Plataforma sem revestimento................................................33

Figura 3 Plataformas grafíticas revestidas termicamente com $250 \mu \mathrm{g} \mathrm{W}+200 \mu \mathrm{g}$ Rh e co-injeção de $5 \mu \mathrm{g}$ Rh. (A) plataforma nova; (B) após 150 ciclos de aquecimento e pirólise à $700^{\circ} \mathrm{C}$ durante 10s; (C) após 300 ciclos de aquecimento e pirólise à $700^{\circ} \mathrm{C}$ durante $35 \mathrm{~s} ;$ (D) após 450 ciclos de aquecimento e

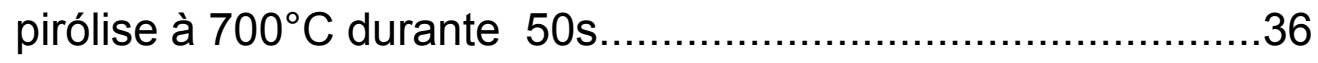

Figura 4 Variações das medidas de absorbância observadas na utilização da plataforma grafítica móvel revestida termicamente com $250 \mu \mathrm{g} \mathrm{W}+200 \mu \mathrm{Rh}$ durante 450 ciclos de aquecimento. Cada ponto representa a média de 10 medidas consecutivas. 
Figura 5 Curvas de temperatura de pirólise $\left(\mathrm{T}_{\text {atomização }}=1800^{\circ} \mathrm{C}\right)$ eatomização $\left(\mathrm{T}_{\text {pirólise }}=1000^{\circ} \mathrm{C}\right)$ para $10 \mu \mathrm{l}$ de solução $50 \mu \mathrm{g} \mathrm{I}^{-1}$ $\mathrm{Pb}$ em 0,2\% v/v $\mathrm{HNO}_{3}$ contendo $8 \% \mathrm{~m} / \mathrm{v}$ de açúcar. ( $\mathbf{\Delta}$ ) Adição de $10 \mu \mathrm{l}$ de solução $0,05 \% \mathrm{v} / \mathrm{v} \mathrm{Pd}+0,03 \% \mathrm{v} / \mathrm{v} \mathrm{Mg}\left(\mathrm{NO}_{3}\right)_{2}$ (घ) Modificador permanente $250 \mu \mathrm{g} \mathrm{W}+200 \mu \mathrm{g}$ Rh e co-injeção de $5 \mu \mathrm{R}$ Rh em solução. 38

Figura 6 Sinais de absorção atômica e de absorção de fundo (BG) observados para determinação de chumbo com plataforma Universal revestida termicamente com $250 \mu \mathrm{g} \mathrm{W}+200 \mu \mathrm{g}$ Rh e co-injeção de $5 \mu \mathrm{gh}\left(\mathrm{T}_{\text {pirólise }}=1000^{\circ} \mathrm{C} ; \mathrm{T}_{\text {atomização }}=1700^{\circ} \mathrm{C}\right)$. (A) $10 \mu \mathrm{l}$ de solução aquosa $50 \mu \mathrm{g} \mathrm{I}{ }^{-1} \mathrm{~Pb}$ em $0,2 \% \mathrm{v} / \mathrm{v} \mathrm{HNO}_{3}$ (B) $10 \mu \mathrm{l}$ de solução $8 \% \mathrm{~m} / \mathrm{v}$ de açúcar com $50 \mu \mathrm{g} \mathrm{I}^{-1} \mathrm{~Pb}$ em $0,2 \% \mathrm{v} / \mathrm{v} \mathrm{HNO}_{3}$ 40

Figura 7 Curvas analíticas de calibração de chumbo utilizando-se plataforma grafítica com modificador permanente $\mathrm{W}+\mathrm{Rh}$ e coinjeção de $5 \mu \mathrm{g}$ de $\operatorname{Rh}\left(\mathrm{T}_{\text {atomização }}=1700^{\circ} \mathrm{C} ; \mathrm{T}_{\text {pirólise }}=1000^{\circ} \mathrm{C}\right)$. (O) $20 \mu \mathrm{l}$ de solução aquosa $50 \mu \mathrm{g} \mathrm{I}^{-1} \mathrm{~Pb}$ em $0,2 \% \mathrm{v} / \mathrm{v} \mathrm{HNO}_{3}$ $(r=0,9981)$. (A ) $20 \mu \mathrm{l}$ de solução $8 \% \mathrm{~m} / \mathrm{v}$ de açúcar $50 \mu \mathrm{g} \mathrm{I}^{-1}$ $\mathrm{Pb}$ em 0,2 \% v/v $\mathrm{HNO}_{3}(\mathrm{r}=0,9983)$

Figura 8 Vida útil do tubo de grafite. Plataforma Universal revestida termicamente com W+Rh e co-injeção de $5 \mu \mathrm{g}$ Rh em cada ciclo de aquecimento. Cada ponto representa a média de 10 leituras de absorbância. Injeção de $10 \mu \mathrm{l}$ de solução $50 \mu \mathrm{g} \mathrm{I}^{-1}$ em 8,0 \% $\mathrm{m} / \mathrm{v}$ de açúcar. 
Figura 9 Vida útil do tubo de grafite. Plataforma com adição de $10 \mu \mathrm{l}$ de solução $0,05 \% \mathrm{v} / \mathrm{v} \mathrm{Pd}+0,03 \% \mathrm{v} / \mathrm{v} \mathrm{Mg}\left(\mathrm{NO}_{3}\right)_{2}$. Cada ponto representa a média de 10 leituras de absorbância. Injeção de $10 \mu \mathrm{l}$ de solução $50 \mu \mathrm{g} \quad \mathrm{I}^{-1}$ em $8,0 \quad \% \quad \mathrm{~m} / \mathrm{v} \quad \mathrm{de}$ açúcar

Figura 10 Tubo de grafite modelo Universal com plataforma integrada. (A) Novo. (B) Após 1070 ciclos de aquecimento, utilizando modificação permanente (W+Rh). (C) Após 1300 ciclos de aquecimento, utilizando modificação convencional $(\mathrm{Pd}+\mathrm{Mg})$ 


\section{LISTA DE TABELAS}

Página

Tabela 1. Programa de aquecimento para determinação de chumbo em fermentado de açúcar utilizado no método proposto por Morris et al. (1976)...........................................................

Tabela 2. Programa de aquecimento para determinação direta de chumbo em açúcar proposto por Miller-Ihli \& Greene (1993)....6

Tabela 3. Programa de aquecimento para determinação de chumbo em açúcar proposto por Miller-Ihli (1994).....................................

Tabela 4. Programa de aquecimento para determinação de chumbo em mel proposto por Viñas et al. (1997)........................................

Tabela 5. Programa de aquecimento para determinação direta de chumbo em açúcar proposto por Lima et al. (1998).

Tabela 6. Propriedades físicas dos metais do grupo da platina (PGMs) usados como modificadores químicos

Tabela 7. Programa de aquecimento utilizado para atomização de chumbo, e obtenção da curva de temperatura de pirólise 30 
Tabela 8. Programa de aquecimento utilizado para avaliação da formação de resíduos carbonáceos sobre plataforma móvel revestida termicamente com $250 \mu \mathrm{g} \mathrm{W}+200 \mu \mathrm{g}$ Rh e co-injeção de $5 \mu \mathrm{g}$ Rh em solução 35

Tabela 9. Programa de aquecimento para determinação direta de chumbo em açúcar utilizando tubo de grafite modelo Universal com plataforma integrada e modificação química convencional ou

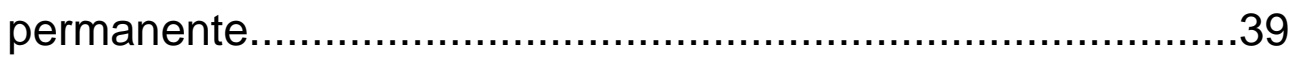

Tabela 10. Figuras analíticas de mérito entre métodos para determinação direta de chumbo em amostras de açúcar

Tabela 11. Custos analíticos para 10000 determinações utilizando modificador permanente $\mathrm{W}+\mathrm{Rh}$ e co-injeção de Rh (THGA endcapped) Perkin-Elmer versus modificação convencional $\mathrm{Pd}+\mathrm{Mg}$, tubo de grafite modelo Universal. 48

Tabela 12. Comparação dos resultados na determinação direta de chumbo em açúcar com adição de $5 \mu \mathrm{g} \mathrm{I}^{-1} \mathrm{~Pb}$ utilizando superfície grafite revestida com $\mathrm{W}+\mathrm{Rh}{ }^{\text {(a), modificação }}$ convencional de $\mathrm{Pd}+\mathrm{Mg}^{(b)}$ e método proposto por Lima et al. (1998) $^{(c)}$ 


\section{LISTA DE ABREVIAÇÕES}

ETAAS - Espectrometria de Absorção Atômica com Atomização Eletrotérmica.

GFAAS - Espectrometria de Absorção Atômica com Forno de Grafite.

THGA - Tubo de Grafite com Aquecimento Transversal (Perkin Elmer).

THGA "standard" - Tubo de grafite com aquecimento transversal do tipo padrão (Perkin Elmer).

THGA "end-capped" - Tubo de grafite tipo THGA com aberturas laterais restritivas (Perkin Elmer).

BG - Background, absorção de fundo.

FAAS - Espectrometria de Absorção Atômica com Chama.

SEM - Microscopia Eletrônica de Varredura.

Tubo de grafite com plataforma adaptada - Plataforma grafitica a qual é inserida e adaptada ao tubo de grafite.

Tubo de grafite com plataforma integrada - Plataforma grafitica que compõem o tubo de grafite 


\title{
DETERMINAÇÃO DE CHUMBO EM AÇÚCAR POR ESPECTROMETRIA DE ABSORÇÃO EM FORNO DE GRAFITE TRATADO COM TUNGSTÊNIO E RÓDIO
}

\author{
Autor: PAULINO FLORÊNCIO DE SOUZA \\ Orientador: Prof. Dr. FRANCISCO JOSÉ KRUG
}

\section{RESUMO}

Um método de baixo custo é proposto para determinação direta de chumbo em açúcar por espectrometria de absorção atômica com forno de grafite e correção de fundo com fonte de deutério, empregando modificação química permanente com $250 \mu \mathrm{g} \mathrm{W}+200 \mu \mathrm{g} R \mathrm{e}$ co-injeção de $5 \mu \mathrm{g} \mathrm{Rh}$. Os experimentos foram realizados com plataforma integrada ou ao no tubo de grafite com aquecimento longitudinal. Para avaliação da modificação química permanente, foram feitos experimentos na ausência de modificação e na presença de modificação química convencional com $\mathrm{Pd}+\mathrm{Mg}$. No decorrer do trabalho observou-se ser imprescindível a co-injeção de Rh para a estabilização térmica de chumbo na presença de açúcar.

A amostra (8 g) é dissolvida em $100 \mathrm{ml}$ de solução aquosa $0,2 \% \mathrm{v} / \mathrm{v} \mathrm{HNO}_{3}$, e uma alíquota de $10 \mu \mathrm{l}$ é injetada com $5 \mu \mathrm{l}$ de solução de Rh na plataforma do tubo de grafite modelo Universal da Varian tratada com W e Rh. A massa característica $\left(m_{0}\right)$ e o limite de detecção do método foram $11 \mathrm{pg} \mathrm{Pb}$ e $5 \mathrm{ng} \mathrm{g}^{-1}$ respectivamente, e a vida útil do tubo de grafite foi de 860 queimas. O método apresentou boa reprodutibilidade com coeficiente de variação inferior a 2,5 \% $(n=3)$. As 
características analíticas foram comparadas com os métodos recomendados na literatura. A exatidão do método proposto para determinação direta de chumbo em açúcar foi avaliada pela comparação com método convencional utilizando $\mathrm{Pd}+\mathrm{Mg}$ e nenhuma diferença estatística foi observada aplicando-se o teste $t$ de Student ao nível de 95\% de probabilidade, em amostras que receberam adição de chumbo. 


\title{
DETERMINATION OF LEAD IN SUGAR BY GRAPHITE FURNACE ATOMIC ABSORPTION SPECTROMETRY (GFAAS) TREATED WITH TUNGSTEN-RHODIUM
}

\author{
Author: PAULINO FLORÊNCIO OF SOUZA \\ Advisor: Prof. Dr. FRANCISCO JOSÉ KRUG
}

\section{SUMMARY}

A simple method for the direct determination of lead in sugar by graphite furnace atomic absorption spectrometry (GFAAS) with platform treated with $250 \mu \mathrm{g} \mathrm{W}+200 \mu \mathrm{g} \mathrm{Rh}$ and deuterium background correction is proposed. Samples $(8 \mathrm{~g})$ were dissolved in $100 \mathrm{ml}$ of an aqueous solution containing $0,2 \% \mathrm{v} / \mathrm{v} \mathrm{HNO}_{3}$ and $10 \mu \mathrm{l}$ aliquots were co-injected with $5 \mu \mathrm{g} R$ into the integrated platform modified with W-Rh of the Universal Varian longitudinal heated graphite atomizer. The characteristic mass $\left(m_{0}\right)$ and the method detection limit were $11 \mathrm{pg} \mathrm{Pb}$ and 5,0 $\mathrm{ng} \mathrm{g}^{-1}$ $\mathrm{Pb}$, respectively, and the tube life time was 860 firings. The relative standard deviation of measurements $(n=3)$ was lower than $2,5 \%$.

For the evaluation of the permanent chemical modifier, parallel experiments were carried in the presence of diluted nitric acid and with the conventional $\mathrm{Pd}+\mathrm{Mg}$ chemical modifier. Experiments were made either with manual inserted graphite plataforms or integrated plataforms into longitudinal graphite tubes.

Comparison of the proposed method with a method based on $\mathrm{Pd}+\mathrm{Mg}$ chemical modifier showed no statistical differences by applying a $t$-test at 95\% confidence level, for sugar sample solution spiked with lead. 


\section{INTRODUÇÃO}

O Brasil é o maior produtor de cana de açúcar do mundo, com 4,5 milhões de hectares cultivados. (Unica - União da Agroindústria Canavieira de São Paulo, 2002).

A cana demora para ser colhida de um a um ano e meio em média, e as regiões do Centro-Sul e Norte-Nordeste são as maiores produtoras. No Brasil existem 307 usinas de açúcar, das quais 128 encontram-se no Estado de São Paulo. Apenas 45\% da cana brasileira são transformadas em açúcar. O Estado de São Paulo é o maior produtor (60\%), sendo responsável por 70\% da exportação brasileira. Com estas vantagens, o Brasil tornou-se o maior produtor e exportador de açúcar do mundo (Única, 2002), com 33\% do mercado internacional (Vasconcelos, 2002).

No ano de 2000, o país exportou US\$1,2 bilhões, sendo a Rússia o maior importador de açúcar do Brasil (Unica, 2002).

No Brasil o consumo de açúcar é de $52 \mathrm{~kg}$ per capita, mas a média mundial é de $22 \mathrm{~kg}$ per capita. O açúcar é um material orgânico constituído por 99,02\% de sacarose (Lajolo \& Menezes, 2001).

Sendo o açúcar um componente importante na dieta brasileira e de destaque na pauta de exportações, o controle de sua qualidade tornase imprescindível. De acordo com a FAO/WHO CODEX ALIMENTARIUS COMMISSION (1995) a concentração máxima de chumbo permitida no 
açúcar varia de $0,1 \mu \mathrm{g} \mathrm{g}^{-1}$ em dextrose e frutose, a $0,5 \mu \mathrm{g} \mathrm{g}^{-1}$ em xaropes de glicose, sacarose e xaropes de frutose de milho. A Agência Nacional de Vigilância Sanitária (ANVISA) através da portaria no 685, de 27 de agosto de 1998 estabelece os limites toleráveis para o chumbo dextrose (glucose) em até $2,0 \mathrm{mg} \mathrm{kg}^{-1}$, e a National Academy of Sciences (1996) em até $0,5 \mu \mathrm{g} \mathrm{g}^{-1} \mathrm{~Pb}$.

A possível presença de chumbo no açúcar pode ser oriunda dos insumos agrícolas utilizados segundo Alloway (1995), o chumbo está presente no solo com concentrações $<20 \mathrm{mg} \mathrm{kg}^{-1}$. As plantas podem absorver este metal dependendo do tempo de exposição, das características climáticas e físico-químicas do solo, da espécie da planta e de sua anatomia. O chumbo não é um elemento essencial para o ser humano, porém a exposição ao chumbo é uma preocupação à saúde pública devido aos efeitos maléficos que pode provocar. Em crianças, à medida que aumenta o grau de contaminação, agravam-se os sintomas de dificuldade de aprendizagem, apatia, dores de cabeça, convulsões, perda de audição, comportamento agressivo, retardamento mental, dores abdominais e nas articulações, nefropatia e eventualmente morte. Uma vez absorvido pela corrente sangüínea, mais de 95\% fica ligado aos eritrócitos, causando aumento da fragilidade e redução do tempo de vida das células. Possui grande afinidade por ossos, onde sua concentração aumenta durante a vida. A excreção é feita principalmente via urinária.

Em adultos os sintomas relatados na literatura médica são hipertensão, desordens no sistema nervoso, perda de memória, irritabilidade, dores de cabeça, encelopatia, esterilidade, impotência, nefropatia, anemia e diminuição da longevidade (Bechara, 2004). 
O chumbo ocorre naturalmente no meio ambiente, mas a atividade industrial tem sido a responsável por problemas causados por esse metal. No Brasil, a maior parte de chumbo encontrado na natureza era proveniente da emissão de escapamentos de automóveis quando ainda era permitido o uso do tetraetila de chumbo nos combustíveis. Outra fonte de contaminação de chumbo no ar provém da queima de carvão, óleo, processos industriais e lixo. Além disso, a contaminação poderá ocorrer pela eliminação de rejeitos industriais, principalmente das indústrias de baterias e reciclagem de metais (Barbosa Júnior, 2003). A contaminação dos solos urbanos por chumbo pode ser derivada de fumos industriais, baterias, plásticos, borrachas e inseticidas (Alloway, 1995).

Tendo em vista os prejuízos causados à saúde humana e suas graves consequências sócio-econômicas a agência americana EPA (Environmental Protection Agency) e outras organizações governamentais estabeleceram limites toleráveis de chumbo no $\operatorname{ar}\left(<1,5 \mu \mathrm{m} \mathrm{m}^{-3}\right)$, em água potável $\left(<15 \mu \mathrm{g} \mathrm{I}^{-1}\right)$ e em tintas $(<0.06 \%)$ (Bechara, 2004).

Nos Estados Unidos, o Centro de Controle e Prevenção de Doenças (CDC - Centers for Diseases Control and Prevention) alterou o limite máximo permitido de chumbo no sangue de crianças de 25 para $10 \mu \mathrm{g} \mathrm{dl}^{-1}$ que outrora tinham sido considerados seguros. 


\section{REVISÃO DE LITERATURA}

O controle do teor de chumbo e de outros elementos tóxicos em açúcar por laboratórios especializados é realizado por um número escasso de métodos analíticos. Grande parte dos trabalhos publicados na literatura utiliza a espectrometria de absorção atômica com chama (FAAS) e espectrometria de absorção atômica com atomização eletrotérmica (ETAAS) empregando forno de grafite. Atualmente, já existem vários laboratórios brasileiros equipados com fornos de grafite.

Em 1976, Morris et al. propuseram o primeiro método para determinação de chumbo, cádmio e zinco em açúcar por GFAAS, empregando a decomposição microbiológica da amostra com levedura, para eliminar as interferências de matriz. Os produtos formados durante a decomposição, como dióxido de carbono e etanol, foram facilmente removidos da solução. O método consistia em dissolver $5 \mathrm{~g}$ de açúcar em $35 \mathrm{ml}$ de água desionizada, ajustar o pH entre 4,5-5,0 com 10\% v/v ácido acético, adicionar $0,25 \mathrm{~g}$ de fermento à solução de açúcar, e realizar a fermentação a $40^{\circ} \mathrm{C}$ durante 1 noite. A solução que sofria o processo fermentativo era avolumada para balão volumétrico de $50 \mathrm{ml}$ com água desionizada, e em seguida centrifugada para separação do fermento. Brancos de fermento sem a presença de açúcar eram preparados paralelamente. Desta forma, obtinha-se uma solução equivalente a $10 \% \mathrm{~m} / \mathrm{v}$ de açúcar fermentado. A Tabela 1 mostra o programa de aquecimento utilizado no método proposto. 
Tabela 1. Programa de aquecimento para determinação de chumbo em fermentado de açúcar utilizado no método proposto por Morris et al. (1976)

\begin{tabular}{cccc}
\hline Etapa & Temperatura $\left({ }^{\circ} \mathrm{C}\right)$ & Rampa (s) & Gás de proteção \\
\hline 1 & 100 & 30 & Nitrogênio \\
2 & 400 & 60 & Nitrogênio \\
3 & 2000 & 10 & Nitrogênio \\
\hline
\end{tabular}

Alíquotas de 5 - $50 \mu \mathrm{l}$ foram introduzidas no forno de grafite com auxílio de uma micropipeta. Utilizou-se uma lâmpada de cátodo oco de chumbo no comprimento de onda 217.7 nm e lâmpada de deutério como corretor de fundo. O gás de proteção foi o nitrogênio. A concentração de chumbo foi determinada utilizando-se curvas analíticas preparadas com soluções aquosas e pelo método das adições de analito a recuperação foi em média $97 \pm 7 \%$.

Em 1976 Souza et al. determinaram cálcio, magnésio, alumínio, manganês, ferro e cobre em amostras de açúcar de 5 usinas localizadas no Estado de São Paulo por FAAS. O método consistia em dissolver $5 \mathrm{~g}$ de açúcar em $100 \mathrm{ml}$ de ácido clorídrico 0,1 $\mathrm{mol} \mathrm{I}^{-1}$. Desta forma, obtinhase uma solução equivalente a $5 \% \mathrm{~m} / \mathrm{v}$ de açúcar que era aspirada diretamente pelo nebulizador pneumático do espectrômetro de absorção atômica Perkin-Elmer modelo 306 B.

Em 1993, Miller-Ihli \& Greene propuseram um método simples para determinação direta de chumbo em açúcar e melaço por ETAAS com forno de grafite com aquecimento longitudinal e efeito Zeeman como corretor de fundo. Soluções de sucrose e frutose de milho foram preparadas usando partes iguais, sendo solubilizadas em $5 \% \mathrm{v} / \mathrm{v}$ de 
$\mathrm{HNO}_{3}$ purificado, evitando-se possível contaminação, e empregando-se oxigênio na etapa de pirólise para dispensar a decomposição da amostra por via úmida. Injetaram-se $20 \mu \mathrm{l}$ da solução de açúcar sobre a plataforma grafitica, seguindo-se a co-injeção de $5 \mu \mathrm{l}$ da solução do modificador $2 \% \quad \mathrm{v} / \mathrm{v} \quad \mathrm{Mg}\left(\mathrm{NO}_{3}\right)_{2}$. Este método foi comparado analisando-se soluções de sucrose e frutose com adição de massas conhecidas de chumbo após a decomposição convencional, com recuperação média de $100 \pm 5 \%$. O limite de detecção e a massa característica do método proposto foram, respectivamente, $0,9 \mathrm{ng} \mathrm{g}^{-1} \mathrm{~Pb}$ e $12 \mathrm{pg} \mathrm{Pb}$. Devido à pirólise $\left(750^{\circ} \mathrm{C}\right)$ assistida por oxigênio, a vida útil do tubo de grafite não excedia 100 queimas. A Tabela 2, mostra o programa de aquecimento com pirólise assistida por oxigênio utilizado por Miller-Ihli \& Greene (1993).

Tabela 2. Programa de aquecimento para determinação direta de chumbo em açúcar proposto por Miller-Ihli \& Greene (1993)

\begin{tabular}{ccccc}
\hline Etapa & $\begin{array}{c}\text { Temperatura } \\
\left({ }^{\circ} \mathrm{C}\right)\end{array}$ & $\begin{array}{c}\text { Rampa } \\
(\mathrm{s})\end{array}$ & $\begin{array}{c}\text { Patamar } \\
(\mathrm{s})\end{array}$ & $\begin{array}{c}\text { Tipo de gás } \\
\left(\mathrm{ml} \mathrm{min}^{-1}\right)\end{array}$ \\
\hline 1 & 200 & 20 & 30 & Argônio (300) \\
2 & 750 & 40 & 40 & Ar sintético (300) \\
3 & 20 & 1 & 60 & Argônio (300) \\
4 & 1800 & 0 & 6 & 0 \\
5 & 2600 & 1 & 7 & Argônio (300) \\
6 & 20 & 1 & 5 & Argônio (300) \\
\hline
\end{tabular}


Posteriormente, Miller-Ihli em 1994 propôs um método para determinação de chumbo em açúcar e melaço por ETAAS, empregando forno de grafite com aquecimento longitudinal, e correção de fundo por efeito Zeeman, após a decomposição da amostra por via úmida. Neste procedimento, transferiram-se $5 \mathrm{~g}$ da amostra para tubo de polipropileno, adicionou-se $0,75 \mathrm{ml}$ de solução $50 \% \mathrm{v} / \mathrm{v} \mathrm{HNO}_{3}$ purificado, mantendo-se em banho-maria durante 20 a 30 min entre 90 e $95^{\circ} \mathrm{C}$ até cessar a liberação de fumos de $\mathrm{NO}_{2}$. Após a amostra ser resfriada à temperatura ambiente, adicionou-se, lentamente, uma alíquota de $0,5 \mathrm{ml}$ de solução $50 \% \mathrm{v} / \mathrm{v} \mathrm{H}_{2} \mathrm{O}_{2}$, colocou-se em banho-maria entre 90 e $95^{\circ} \mathrm{C}$ por um período de aproximadamente $5 \mathrm{~min}$, seguindo-se resfriamento até a temperatura ambiente. Uma segunda alíquota de $0,5 \mathrm{ml}$ de $50 \% \mathrm{v} / \mathrm{v} \mathrm{H}_{2} \mathrm{O}_{2}$ foi adicionada, mantendo-se a solução em banho-maria entre 90 e $95^{\circ} \mathrm{C}$ por aproximadamente $10 \mathrm{~min}$, ou até obter uma solução incolor.

Após o resfriamento, as amostras foram diluídas a $10 \mathrm{ml}$, obtendo-se uma solução equivalente a $50 \% \mathrm{~m} / \mathrm{v}$ de açúcar digerido. O método envolveu o uso de $20 \mu \mathrm{l}$ de solução e $5 \mu \mathrm{l}$ do modificador $2 \% \mathrm{~m} / \mathrm{v} \mathrm{Mg}\left(\mathrm{NO}_{3}\right)_{2}$, sendo que oxigênio foi utilizado na etapa de pirólise durante $60 \mathrm{~s}$ a $750^{\circ} \mathrm{C}$ para auxiliar a decomposição do açúcar. A massa característica $\left(m_{\circ}\right)$ e limite de detecção foram, respectivamente, $12 \mathrm{pg} \mathrm{Pb}$ e $3.3 \mathrm{ng} \mathrm{g}^{-1} \mathrm{~Pb}$. A Tabela 3 mostra o programa de aquecimento com pirólise assistida por oxigênio utilizado por Miller-Ihli (1994). 
Tabela 3. Programa de aquecimento para determinação de chumbo em açúcar proposto por Miller-Ihli (1994)

\begin{tabular}{ccccc}
\hline Etapa & $\begin{array}{c}\text { Temperatura } \\
\left({ }^{\circ} \mathrm{C}\right)\end{array}$ & $\begin{array}{c}\text { Rampa } \\
(\mathrm{s})\end{array}$ & $\begin{array}{c}\text { Patamar } \\
(\mathrm{s})\end{array}$ & $\begin{array}{c}\text { Tipo de gás } \\
\left(\mathrm{ml} \mathrm{min}^{-1}\right)\end{array}$ \\
\hline 1 & 200 & 20 & 30 & Argônio (300) \\
2 & 750 & 40 & 40 & Ar sintético (300) \\
3 & 20 & 1 & 60 & Argônio (300) \\
4 & 1800 & 0 & 8 & 0 \\
5 & 2600 & 1 & 7 & Argônio (300) \\
6 & 20 & 1 & 5 & Argônio (300) \\
\hline
\end{tabular}

Em 1995 a performance do método foi avaliada em estudo inter-laboratorial, onde quantidades acima de $0,5 \mu \mathrm{g} \mathrm{g} \mathrm{g}^{-1} \mathrm{~Pb}$ foram adicionadas às amostras de sucrose e frutose de milho e enviadas para 12 laboratórios. Os dados recebidos de apenas 8 laboratórios foram analisados, utilizando-se o manual de estatística da AOAC (Association of Official Analytical Chemists). A precisão do método foi de $9,6 \%$ e a recuperação de chumbo foi em média $115 \%$. Por proporcionar melhores limites de detecção e precisão, o método proposto foi recomendado e aceito pelo Food Chemicals Codex (FCC) para quantificar níveis $\geq 100 \mathrm{ng} \mathrm{g}^{-1} \mathrm{~Pb}$ em amostras de sucrose e frutose de milho.

Em 1997, Viñas et al. propuseram um método para determinação de chumbo, cádmio, zinco e cobre em mel por ETAAS com forno de grafite longitudinal. Utilizou-se um banho-maria para homogeneizar as amostras de mel, cujas massas variavam para determinação de cobre, cádmio ou chumbo $(1,0$ - 1,5g) e zinco $(0,1-0,2 g)$. Cada amostra foi transferida para balão volumétrico de 
$25 \mathrm{ml}$, sendo adicionados $250 \mu \mathrm{l}$ de $65 \% \mathrm{~m} / \mathrm{v} \mathrm{HNO}_{3}$ concentrado $+2,5 \mathrm{ml}$ de $33 \% \mathrm{~m} / \mathrm{v} \mathrm{H} \mathrm{H}_{2}+25 \mathrm{mg}$ de $\mathrm{NH}_{4} \mathrm{H}_{2} \mathrm{PO}_{4}$ para determinações de cádmio, chumbo e zinco, e o volume completado com água. As amostras foram sonicadas durante $5 \mathrm{~min}$, e $20 \mu \mathrm{l}$ da solução obtida foram introduzidos diretamente no forno de grafite longitudinal, utilizando-se a lâmpada de deutério para correção de fundo.

Soluções aquosas de referência foram utilizadas para determinação de cádmio, chumbo e zinco contendo $1 \% \mathrm{v} / \mathrm{v} \mathrm{HNO}_{3}$, $50 \% \mathrm{v} / \mathrm{v} \mathrm{H} \mathrm{H}_{2}$ e $0,1 \% \mathrm{~m} / \mathrm{v} \mathrm{NH}_{4} \mathrm{H}_{2} \mathrm{PO}_{4}$. Somente a solução de referência para determinar cádmio continha frutose $2 \% \mathrm{~m} / \mathrm{v}$. O programa de aquecimento foi estabelecido com soluções contendo $4 \% \mathrm{~m} / \mathrm{v}$ de mel. $\mathrm{O}$ limite de detecção foi de $1,4 \mathrm{ng} \mathrm{ml}^{-1} \mathrm{~Pb}$. A Tabela 4 mostra o programa de aquecimento para determinação de chumbo.

Tabela 4. Programa de aquecimento para determinação de chumbo em mel proposto por Viñas et al. (1997)

\begin{tabular}{ccccc}
\hline Etapa & $\begin{array}{c}\text { Temperatura } \\
\left({ }^{\circ} \mathrm{C}\right)\end{array}$ & $\begin{array}{c}\text { Rampa } \\
(\mathrm{s})\end{array}$ & $\begin{array}{c}\text { Patamar } \\
(\mathrm{s})\end{array}$ & $\begin{array}{c}\text { Vazão de argônio } \\
\left(\mathrm{ml} \mathrm{min}^{-1}\right)\end{array}$ \\
\hline 1 & 400 & 10 & 20 & 200 \\
2 & 1200 & 5 & 20 & 200 \\
3 & 1800 & 0 & 3 & 0 \\
4 & 2650 & 1 & 3 & 200 \\
\hline
\end{tabular}


Em 1998, Lima et al. propuseram um método para determinação direta de chumbo em amostras com elevados teores de açúcar, tais como suco de fruta artificial, xarope e mel, empregando-se ETAAS com forno de grafite com aquecimento transversal (THGA endcapped) e utilizando, como modificador, a mistura 0,05\% m/v Pd + $0,03 \% \mathrm{~m} / \mathrm{v} \mathrm{Mg}\left(\mathrm{NO}_{3}\right)_{2}$. Experimentos preliminares foram realizados com soluções de 4,0 a $16,0 \% \mathrm{~m} / \mathrm{v}$ em açúcar para avaliar os efeitos da massa de açúcar que seria introduzida no atomizador. Observou-se que em concentrações superiores a $8,0 \% \mathrm{~m} / \mathrm{v}$ ocorria a formação de depósitos de resíduos carbonáceos na superfície da plataforma grafítica; para concentrações superiores a $16,0 \% \mathrm{~m} / \mathrm{v}$ o tempo de vida útil do atomizador ficava limitado a 100 ciclos de aquecimento, e o coeficiente de variação das medidas (CV) era superior a $10 \%$. Para aumentar a vida útil do atomizador os autores decidiram trabalhar com soluções $8,0 \% \mathrm{~m} / \mathrm{v}$ de açúcar, onde $4 \mathrm{~g}$ de amostra de açúcar eram solubilizadas em água desionizada e acidificadas com $0,2 \% \mathrm{v} / \mathrm{v} \mathrm{HNO}_{3}$. O volume de amostra injetado foi de $20 \mu \mathrm{l}$, co-injetando-se $10 \mu \mathrm{l}$ de solução $0,05 \% \mathrm{~m} / \mathrm{v} \mathrm{Pd}$ $+0,03 \% \mathrm{~m} / \mathrm{v} \mathrm{Mg}\left(\mathrm{NO}_{3}\right)_{2}$. A correção de fundo foi feita empregando-se efeito Zeeman longitudinal. O programa de aquecimento (Tabela 5) foi conduzido com duas etapas de pirólise para determinação de chumbo. $\mathrm{Na}$ primeira etapa foi necessária uma rampa de 180 a $600^{\circ} \mathrm{C}$ e na segunda etapa foi necessária uma rampa de 600 a $1000^{\circ} \mathrm{C}$. Com isto a formação de resíduos carbonáceos não foi perceptível. Nesta situação, a absorção de fundo foi reduzida, sendo possível a realização de 240 a 260 queimas por atomizador. 
Tabela 5. Programa de aquecimento para determinação direta de chumbo em açúcar proposto por Lima et al. (1998)

\begin{tabular}{ccccc}
\hline Etapa & $\begin{array}{c}\text { Temperatura } \\
\left({ }^{\circ} \mathrm{C}\right)\end{array}$ & $\begin{array}{c}\text { Rampa } \\
(\mathrm{s})\end{array}$ & $\begin{array}{c}\text { Patamar } \\
(\mathrm{s})\end{array}$ & $\begin{array}{c}\text { Vazão de argônio } \\
\left(\mathrm{ml} \mathrm{min}^{-1}\right)\end{array}$ \\
\hline 1 & 150 & 5 & 5 & 250 \\
2 & 180 & 5 & 25 & 250 \\
3 & 600 & 5 & 5 & 250 \\
4 & 1000 & 5 & 20 & 250 \\
5 & 1800 & 0 & 5 & 0 \\
6 & 2400 & 1 & 5 & 250 \\
\hline
\end{tabular}

O programa foi comparado com o método recomendado por Miller-Ihli (1994) que empregava uma etapa de pirólise a $750^{\circ} \mathrm{C}$ assistida por oxigênio, proporcionando um tempo de vida útil do atomizador de 105 ciclos de aquecimento. Como era necessária uma etapa de resfriamento e introdução de argônio para eliminar o oxigênio do atomizador, o ciclo do programa de aquecimento era relativamente longo (211-213s), comparativamente ao recomendado por Lima et al. (1998). O limite de detecção e massa característica $\left(m_{\circ}\right)$ dos métodos foram, respectivamente, $7,0 \mathrm{ng} \mathrm{g}^{-1}$ e $15 \mathrm{pg} \mathrm{Pb}$.

Em 1998, Leblebici \& Volkan propuseram três métodos de decomposição por via seca em forno tipo mufla para determinar chumbo, cobre e ferro em açúcar branco por FAAS, como alternativa ao método empregando ETAAS com forno de grafite recomendado por Miller-Ihli (1994). Eles exploraram a possibilidade de se decompor uma grande massa de amostra $(100 \mathrm{~g})$, dissolvendo-se o resíduo final em ácido ou mistura de ácidos e completando-se o volume a apenas $25 \mathrm{ml}$. A 
Figura 1 apresenta os métodos avaliados por Leblebici \& Volkan para o preparo de amostras de açúcar.

Figura 1. Métodos de preparo de amostras de açúcar avaliados por Leblebici \& Volkan (1998)

\begin{tabular}{|c|c|c|}
\hline $\begin{array}{c}\text { Método I } \\
\text { Secagem com } \mathrm{H}_{2} \mathrm{SO}_{4}\end{array}$ & $\begin{array}{c}\text { Métodos II \& III } \\
\text { Secagem com } \mathrm{Mg}\left(\mathrm{NO}_{3}\right)_{2}\end{array}$ & $\begin{array}{c}\text { Método IV } \\
\text { Secagem com } \\
\mathrm{Mg}\left(\mathrm{NO}_{3}\right)_{2}+\mathrm{HNO}_{3}\end{array}$ \\
\hline
\end{tabular}

\begin{tabular}{|c|c|c|}
\hline \multicolumn{3}{|c|}{ Sub-amostragem: pesar $100 \mathrm{~g}$ de açúcar em cápsula de borossilicato e adicionar: } \\
\hline Método I & Métodos II \& III & Método IV \\
\hline $10 \mathrm{ml} \mathrm{H} \mathrm{SO}_{4}$ concentrado & $\begin{array}{l}10 \mathrm{~g} \text { de } \mathrm{Mg}\left(\mathrm{NO}_{3}\right)_{2}+0,2 \mathrm{ml} \mathrm{de} \\
\text { antiespumante } 204\end{array}$ & $\begin{array}{c}10 \mathrm{~g} \text { de } \mathrm{Mg}\left(\mathrm{NO}_{3}\right)_{2}+0,2 \mathrm{ml} \text { de } \\
\text { antiespumante } 204+ \\
5 \mathrm{ml} \text { de } \mathrm{HNO}_{3} \text { concentrado }\end{array}$ \\
\hline \multirow{2}{*}{\multicolumn{3}{|c|}{ Pré carbonização em bico de Bunsen }} \\
\hline & & \\
\hline Método I: $1 \mathrm{~h}$ & Métodos II \& III: $1,5 \mathrm{~h}$ & Método IV: $1,5 \mathrm{~h}$ \\
\hline$\downarrow$ & $\downarrow$ & $\downarrow$ \\
\hline \multicolumn{3}{|c|}{ Calcinação em forno tipo mufla } \\
\hline $\begin{array}{c}\text { Método I: } \\
550^{\circ} \mathrm{C} \text { durante } 2,5 \text { dias } \\
\end{array}$ & $\begin{array}{c}\text { Métodos II \& III: } \\
500^{\circ} \mathrm{C} \text { durante } 1,5 \text { dias }\end{array}$ & $\begin{array}{c}\text { Método IV: } \\
450^{\circ} \mathrm{C} \text { durante } 1,5 \text { dias }\end{array}$ \\
\hline \\
\hline \multicolumn{3}{|c|}{ Solubilização } \\
\hline $\begin{array}{c}\text { Método I } \\
\text { com } 4 \text { ml de } \mathrm{HCl} 6 \mathrm{~mol} \mathrm{I}^{-1}\end{array}$ & $\begin{array}{c}\text { Métodos II \& III } \\
20 \mathrm{ml} \text { de mistura } \\
\mathrm{HCl}, \mathrm{HNO}_{3}, \mathrm{H}_{2} \mathrm{O}(2: 1,5: 6,5)\end{array}$ & $\begin{array}{c}\text { Método IV } \\
20 \mathrm{ml} \text { de mistura } \\
\mathrm{HCl}, \mathrm{HNO}_{3}, \mathrm{H}_{2} \mathrm{O}(2: 1,5: 6,5)\end{array}$ \\
\hline$\downarrow$ & $\downarrow$ & $\downarrow$ \\
\hline \multicolumn{3}{|c|}{ Completar o volume para $25 \mathrm{ml}$ com água desionizada } \\
\hline \multicolumn{3}{|c|}{ Determinar $\mathrm{Pb}, \mathrm{Cu}$, e Fe por FAAS } \\
\hline
\end{tabular}

Os autores recomendam o método I e destacavam que o método II \& III foi o que apresentou maior dificuldade no manuseio, sendo o mais longo comparado ao método de secagem utilizando-se $\mathrm{H}_{2} \mathrm{SO}_{4}$. 
Para avaliar a recuperação de $\mathrm{Pb}$ no método I adicionou-se 1 e $2 \mathrm{mg} \mathrm{kg}^{-1} \mathrm{~Pb}$ em cada amostra; no método II-III adicionavam 2 e $4 \mathrm{mg} \mathrm{kg}^{-1} \mathrm{~Pb}$; no método IV adicionavam $4 \mathrm{mg} \mathrm{kg}^{-1} \mathrm{~Pb}$. A recuperação média de $\mathrm{Pb}$ foi de $91 \pm 2,5 \%$.

\subsection{Modificadores na espectrometria de absorção atômica com forno de grafite (GFAAS)}

Modificadores químicos podem ser definidos como compostos que são introduzidos com a solução da amostra para diminuir drasticamente os efeitos de matriz.

Segundo Volynsky, (2003) o mecanismo de ação da maioria dos modificadores químicos consiste da remoção da matriz da amostra na etapa de pirólise, enquanto os compostos dos analitos permanecem no atomizador. Isto pode ser feito convertendo-se os compostos da matriz em compostos voláteis (conversão de cloretos metálicos em $\mathrm{HCl}$ por exemplo) ou por meio de uma diminuição da volatilidade dos compostos dos analitos. A maioria dos métodos analíticos que empregam GFAAS requer o uso de modificadores químicos, que aumentem a estabilidade térmica do analito. Em geral, quanto maior a temperatura da etapa de pirólise, mais rápida e mais eficiente a remoção da matriz que poderá interferir na etapa de atomização.

O conceito de modificação química foi proposto por Ediger em (1975), originalmente como modificação de matriz (do inglês: "matrix modification"). Ediger propôs o uso do nitrato de amônio como modificador de matriz para volatilizar o cloreto de sódio presente em água de mar em temperaturas abaixo de $500^{\circ} \mathrm{C}$ durante a etapa de pirólise visando à determinação de cobre por GFAAS. Ediger também introduziu 
- níquel como o primeiro modificador metálico para estabilizar termicamente arsênio e selênio (Welz et al,1992).

A modificação química pode ser definida como a introdução de um reagente com a solução da amostra visando à diminuição dos efeitos da matriz (Volynsky, 2003). Os modificadores propiciam a retenção do analito em temperaturas mais elevadas durante a etapa de pirólise, melhorando o processo de atomização.

Os modificadores químicos (convencionais ou permanentes) podem ser empregados de várias formas.

Os modificadores denominados convencionais são utilizados de duas maneiras:

a) Adiciona-se uma alíquota $(5-20 \mu \mathrm{l})$ da solução do modificador no atomizador com a solução da amostra. Neste procedimento os reagentes devem ser de alta pureza.

b) Adiciona-se uma alíquota $(5-20 \mu \mathrm{l})$ da solução do modificador sobre a superfície grafítica; e aplica-se um programa de aquecimento para a secagem e modificação da superfície, posteriormente, faz-se a introdução da solução da amostra sobre a superfície modificada e aplica-se o programa de aquecimento visando à atomização do analito. $\mathrm{O}$ processo é repetido a cada ciclo de aquecimento. Neste procedimento o programa de aquecimento é mais longo e as impurezas presentes no modificador podem ser eliminadas.

Na modificação permanente, o modificador com elevado ponto de ebulição pode ser, por exemplo previamente reduzido sobre a superfície grafítica, e numa etapa subseqüente, a solução da amostra é introduzida no atomizador, semelhante ao item (b) acima descrito. Neste caso, não se necessita injeção do modificador a cada ciclo de 
aquecimento pois a massa depositada é suficiente para permanecer na superfície grafítica por vários ciclos de aquecimento. Cada modificador químico exerce um papel na eliminação de interferências na determinação do analito de interesse empregando GFAAS. As interferências podem ser eliminadas quando, se empregam o uso de uma mistura de dois ou mais modificadores, os quais estabilizam termicamente o analito e apresentam melhor desempenho comparados com os mesmos modificadores utilizados individualmente.

O modificador químico constituído da mistura de $\mathrm{Pd}+\mathrm{Mg}\left(\mathrm{NO}_{3}\right)_{2}$ ou $\mathrm{Pd}+\mathrm{Mg}$, vem sendo empregado em ETAAS como "modificador universal" para determinação de pelo menos 21 elementos (Welz, 1986). Apesar de $\mathrm{Pd}+\mathrm{Mg}$ ser um dos modificadores mais conhecidos, o número de compostos que são utilizados como modificadores é muito grande. Dentre eles os mais eficientes e versáteis pertencem aos seguintes grupos (Volynsky, 2003).

1) Ácido nítrico e oxálico correspondentes aos sais de amônio,

2) Nitratos (exceto do grupo da platina - PGM),

3) Fosfato de amônio,

4) Carbetos com alto ponto de fusão,

5) Compostos orgânicos (principalmente ácido etilenodiaminotetraacético - EDTA, ácido ascórbico e seus sais),

6) Íons dos metais de transição com número de oxidação elevado W (VI), Mo (VI), Zr (IV) etc,

7) Componentes do grupo da platina, exceto Os.

O uso dos modificadores químicos faz parte do conceito STPF (Stabilized Temperature Platform Furnace) proposto por (Slavin et al, 1981), e tem sido essencial para melhorar a seletividade em ETAAS. O conceito STPF inclui: 
a) a evaporação da solução da amostra a partir da superfície de uma plataforma grafítica,

b) o uso da eletrônica rápida para processar os sinais analíticos,

c) Interrupção do fluxo do gás de proteção (argônio) na etapa de atomização,

d) cálculo das concentrações do analito baseada nas medidas de absorbância integrada (área do sinal analítico),

e) uso do corretor de fundo baseado no efeito Zeeman,

f) utilização de atomizadores revestidos com grafite piroliticos,

g) uso de modificador químico (Volynsky, 2003).

É interessante observar que a inclusão dos seis primeiros requerimentos das condições STPF está hoje incorporada nos espectrômetros de absorção comerciais e proporcionada à obtenção de métodos de elevada confiabilidade metrologica. Entretanto um dos mais importantes componentes deste conceito, particularmente o modificador químico, não pode ser incorporado ao projeto de um espectrômetro de absorção atômica com ETAAS (Volynsky, 2003).

Um modificador químico ideal deve apresentar as seguintes características:

a) ser efetivo para um grande número de analitos,

b) ser efetivo para diferentes formas químicas do analito,

c) ter baixa toxidade,

d) ter baixo custo,

e) apresentar estabilidade durante a armazenagem,

f) estabilizar termicamente o analito à máxima temperatura durante a etapa de pirólise,

g) não ser um elemento comumente determinado por ETAAS. (Volynsky, 1998). 
Cabe também ressaltar que a forma química na qual $o$ modificador se encontra na etapa de pirólise, ou mesmo durante o processo de secagem, será de fundamental importância para sua melhor eficiência na estabilização térmica do analito.

Dentre os modificadores utilizados em ETAAS, destacam-se os elementos do grupo da platina (PGMs) ou de metais nobres (Pd, Pt, Rh, Ir, Ru), que tem sido empregados como modificadores convencionais para um grande número de analitos, e os metais de transição (W, Zr, Ta, $\mathrm{Nb}, \mathrm{Ta}, \mathrm{Mo}$ ) formadores de carbetos. Segundo (Volynsky, 1996), três processos são importantes para a ação dos modificadores do grupo da platina (PGMs): redução do modificador, redução do analito e estabilização térmica dos analitos a altas temperaturas. As reações químicas que ocorrem na presença dos modificadores do grupo da platina (PGMs) na estabilização térmica do analito $(A)$ são representadas nas equações de (1) a (6) propostos por Volynsky, 1996.

$$
\mathrm{MY}_{\mathrm{j}}(\mathrm{s})+\mathrm{nC}^{*}(\mathrm{~s}) \rightleftharpoons \mathrm{M}(\mathrm{s})+\mathrm{C}_{\mathrm{n}} \mathrm{Y}_{\mathrm{j}}
$$

$$
\mathrm{A}_{\mathrm{m}} \mathrm{O}_{\mathrm{n}}(\mathrm{s}, l)+\mathrm{M}_{\text {(bulk) }} \rightleftharpoons \mathrm{A}_{\mathrm{m}} \mathrm{O}_{\mathrm{n}} \cdot \mathrm{M}_{\text {(bulk) }}(\mathrm{s}, l)
$$

$$
\mathrm{A}_{\mathrm{m}} \mathrm{O}_{\mathrm{n}} \cdot \mathrm{M}_{(\text {bulk })}(\mathrm{s})+\mathrm{n} / 2 \mathrm{C}^{*}(\mathrm{~s}) \rightleftharpoons m \mathrm{~A}(\mathrm{~s}, \mathrm{l})+n / 2 \mathrm{CO}_{2}(g)+\mathrm{M}(\mathrm{s})
$$

$$
\mathrm{A}_{\mathrm{m}} \mathrm{O}_{\mathrm{n}} \cdot \mathrm{M}_{(\text {bulk })}(\mathrm{s})+\mathrm{n} \mathrm{C}^{*}(\mathrm{~s}) \rightleftharpoons m \mathrm{~A}(\mathrm{~s}, l)+n \mathrm{CO}(g)+\mathrm{M}(\mathrm{s})
$$

solução sólida)

$$
\mathrm{A}_{\mathrm{k}} \mathrm{M}_{\mathrm{q}}(\mathrm{s}) \rightleftharpoons k \mathrm{~A}(g)+q \mathrm{M}(\mathrm{s}, l, g) \text { (atomização) }
$$

Onde: $Y$ é o contra-íon do modificador; $A$ é o analito; $M$ é o modificador na forma de cloreto que é a mais difundida, $C^{*}$ são sítios ativos na superfície grafítica, $s$ representa o estado sólido, I representa o estado líquido, $g$ representa o estado vapor, j, m, n, k, e q são coeficientes estequiométricos. 
Na etapa (1) o modificador químico é reduzido sobre o carbono, entre 800 e $1000^{\circ} \mathrm{C}$, transformando o metal nobre para sua forma elementar. $\mathrm{Na}$ etapa (2), o óxido do analito reage com o modificador formando um aducto, que em etapas posteriores ( 3 e 4) é reduzido pelo carbono, produzindo monóxido e dióxido de carbono, mais o modificador e analito livres, ambos na forma reduzida. Em (5), o modificador e o analito se combinam numa determinada proporção, originando um composto intermetálico analito-modificador e/ou uma solução sólida do analito dissolvida no modificador. A etapa limitante para a atomização é a difusão do analito desta solução sólida, originando átomos no estado fundamental (6). Quanto mais rápida for a reação de redução do óxido do analito catalisada pelo modificador químico (etapas 2,3,e 4), menores serão as perdas do analito por volatilização durante a etapa de pirólise, porque a redução do óxido desta espécie ocorre em temperaturas mais baixas.

Uma outra característica que deve ser destacada é que, se a reação de formação da solução sólida (etapa 5) for lenta, os riscos de perdas do analito por volatilização durante a etapa de pirólise serão maiores. Quanto maior for a temperatura para reduzir o metal nobre (etapa 1), maiores serão as perdas do analito por volatilização, a menos que o modificador esteja previamente reduzido sobre a superfície grafítica. Então, para se obter uma estabilização térmica mais eficaz do analito, quando modificadores constituídos por metal nobre são empregados, é desejável que o modificador esteja previamente reduzido sobre a superfície grafítica. A Tabela 6 , mostra algumas propriedades físicas dos metais do grupo da platina (PGMs). 
Tabela 6. Propriedades físicas dos metais do grupo da platina (PGMs) usados como modificadores químicos

\begin{tabular}{ccc}
\hline PGMs & Ponto de fusão $\left({ }^{\circ} \mathrm{C}\right)$ & Ponto de ebulição $\left({ }^{\circ} \mathrm{C}\right)$ \\
\hline $\mathrm{Pd}$ & 1555 & 2964 \\
$\mathrm{Pt}$ & 1769 & 3827 \\
$\mathrm{Rh}$ & 1963 & 3697 \\
$\mathrm{Ru}$ & 2334 & 4150 \\
$\mathrm{Ir}$ & 2447 & 4428 \\
\hline
\end{tabular}

Outra classe de modificadores, que também catalisam reações de redução de óxidos de analitos, são os carbetos de metais de transição (W, Zr, Ti, Ta, Nb, Mo). As reações (7) a (10) descrevem o mecanismo de carbetos de metais de transição na redução de óxido de analito proposto por (Volynsky, 1996). Os mesmos processos são assumidos para aumentar a estabilização térmica de $\mathrm{Pb}, \mathrm{In}, \mathrm{Sn}, \mathrm{B}$ e Si.

$$
\begin{aligned}
& \text { (7) } 2 \mathrm{MC}(\mathrm{s})+\mathrm{AO}_{2}(\mathrm{~s}) \rightleftharpoons 2 \mathrm{M}(\mathrm{s})+\mathrm{A}(\mathrm{s}, l)+2 \mathrm{CO}(g) \\
& \text { (8) } \mathrm{MC}(\mathrm{s})+\mathrm{AO}(g) \rightleftharpoons \mathrm{M}(\mathrm{s})+\mathrm{A}(\mathrm{s}, l)+2 \mathrm{CO}(g) \\
& \text { (9) } \mathrm{A}(\mathrm{s}, l) \rightleftharpoons \mathrm{A}(g) \\
& \text { (10) } \mathrm{M}(\mathrm{s})+\mathrm{C}(\mathrm{s}) \rightleftharpoons \mathrm{MC}(\mathrm{s})
\end{aligned}
$$

O óxido do analito pode ser reduzido tanto homogeneamente (etapa 7) ou heterogeneamente (etapa 8) pelo carbeto metálico, originando o analito em fase condensada, o qual é posteriormente vaporizado, originando átomos livres do analito (etapa 9). Numa etapa posterior (10) o carbeto metálico é regenerado no ciclo catalítico.

Uma das reações que ocorrem em superfícies grafíticas é a oxidação do carbono a $\mathrm{CO}$ e $\mathrm{CO}_{2}$. $\mathrm{Na}$ presença de modificadores que formam carbetos de metais de transição, estas reações ocorrem em 
temperaturas menores, diminuindo a corrosão da grafite, aumentando o tempo de vida útil do atomizador (Volynsky,1996).

Em 2002, Zhou et al. utilizaram uma mistura contendo $250 \mu \mathrm{g}$ de $\mathrm{W}+200 \mu \mathrm{g}$ de $\mathrm{Rh}$ depositados termicamente no tubo de grafite para determinação de chumbo em sangue realizando 1030 ciclos de aquecimento com o tubo de grafite THGA end-capped, e 965 ciclos de aquecimento com o tubo de grafite THGA standard. Com o modificador convencional de $\mathrm{NH}_{4} \mathrm{H}_{2} \mathrm{PO}_{4}$ realizaram apenas 350 ciclos de aquecimento. Após 250 determinações de chumbo os autores observaram resíduos carbonáceos na plataforma. Novos revestimentos de $250 \mu \mathrm{g}$ de $\mathrm{W}+200 \mu \mathrm{g} \mathrm{Rh}$ foram realizados após 350 ciclos de aquecimento.

Em 1998, Lima et al. utilizaram uma mistura contendo $250 \mu \mathrm{g}$ de $\mathrm{W}+200 \mu \mathrm{g}$ de $\mathrm{Rh}$ depositados termicamente no tubo de grafite, realizando mais de 1700 ciclos de aquecimento para determinação de $\mathrm{Cd}$ em amostras de águas. O modificador permanente W-Rh permaneceu estável por aproximadamente 300 ciclos de aquecimento. Os autores fizeram a comparação do método proposto para determinação de $\mathrm{Cd}$ com - modificador convencional constituído de $3 \mu \mathrm{g} \quad \mathrm{Mg}\left(\mathrm{NO}_{3}\right)_{2}$ +

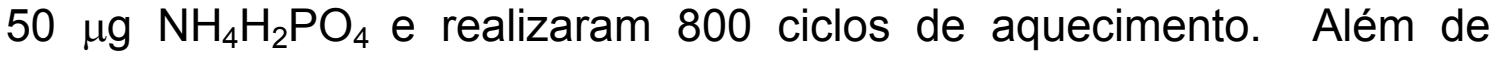
aumentar a vida útil do tubo de grafite, proporcionada pela modificação permanente $\mathrm{W}-\mathrm{Rh}$, o tempo total do programa de aquecimento foi menor em relação ao modificador convencional de $3 \mu \mathrm{g} \mathrm{Mg}\left(\mathrm{NO}_{3}\right)_{2}+50 \mu \mathrm{g}$ $\mathrm{NH}_{4} \mathrm{H}_{2} \mathrm{PO}_{4}$. Posteriormente, Lima et al. (1998) utilizaram o revestimento permanente contendo $250 \mu \mathrm{g} \mathrm{W}+200 \mu \mathrm{g}$ Rh para determinação de Cd em suspensões de peixes (1999), Pb em suspensões de sedimentos (1999), Pb em digeridos biológicos e sedimentos (1999), $\mathrm{Cu}, \mathrm{Pb}$ e Cd em 
extratos obtidos após sonicação de suspensões de sedimentos e materiais biológicos (2000), Cu em sedimentos e materiais biológicos (2001), Cu em sedimentos (2001) e Cu em materiais biológicos (2002), demonstrando a viabilidade do modificador permanente em diversas matrizes. Em 2003 Santos Júnior et al, propuseram um método para determinar $\mathrm{Cu}, \mathrm{Pb}$ e $\mathrm{Mn}$ em amostras de suspensões de dentes, utilizando como modificador permanente, depositado termicamente, a mistura de $250 \mu \mathrm{g} \mathrm{W}+200 \mu \mathrm{g}$ Rh. O modificador permaneceu estável por 300 ciclos de aquecimento. A temperatura de atomização para o chumbo foi de $1700^{\circ} \mathrm{C}$.

Em 2001, Dakukazu et al. desenvolveram um método simples e rápido utilizando solução $0,1 \% \mathrm{~m} / \mathrm{v} \mathrm{Pd}$ como modificador químico para determinação direta de As em açúcar por ETAAS. Alíquota de $60 \mu \mathrm{l}$ de solução de açúcar $8 \% \mathrm{~m} / \mathrm{v}$ em $0,2 \% \mathrm{v} / \mathrm{v}$ de $\mathrm{HNO}_{3}$ e $5 \mu \mathrm{l}$ do modificador químico era co-injetada em forno de grafite THGA end-capped, sendo que o oxigênio foi utilizado na etapa de pirólise durante $40 \mathrm{~s}$ a $600^{\circ} \mathrm{C}$ para evitar a formação de resíduos carbonáceos. Nessas condições a vida útil do tubo de grafite foi de aproximadamente 280 ciclos de aquecimento, e o limite de detecção e massa característica foram respectivamente $0,08 \mathrm{\mu g} \mathrm{l}^{-1}$ e $24 \mathrm{pg}$ As. Para comparar o método proposto, $250 \mathrm{mg}$ da amostra com adição de $0,5 \mu \mathrm{g} \mathrm{I}^{-1}$ As foi decomposta em forno de microondas. Após o resfriamento, a amostra foi diluída a $5 \mathrm{ml}$ com água desionizada obtendo-se uma solução equivalente a $5 \% \mathrm{~m} / \mathrm{v}$ de açúcar digerido e posteriormente analisada por ETAAS. A recuperação se situava entre 86 a $98 \%$.

Em 1996, Bulska et al. investigaram os metais nobres ( $\mathrm{Pd}, \mathrm{Au}, \mathrm{Rh}$, e Ir) para determinação de mercúrio em material certificado de solos SRM 2711 (NIST, USA) por ETAAS. Os autores compararam a 
mistura de $\mathrm{Au}+\mathrm{Rh}$ eletrodepositados com o modificador constituído por $\mathrm{Pd}$ depositado termicamente no tubo de grafite. Constatou-se que a vida útil do tubo de grafite, utilizando o $\mathrm{Pd}$ depositado termicamente $\mathrm{e}$ temperaturas inferiores a $1800^{\circ} \mathrm{C}$, era de 50 ciclos de aquecimento. Por outro lado a mistura de $\mathrm{Au}+\mathrm{Rh}$ eletrodepositado poderia ser utilizada por mais de 500 ciclos de aquecimento com temperaturas de atomização acima de $2000^{\circ} \mathrm{C}$.

Em 2002, Magalhães et al. propuseram o modificador permanente constituído de $500 \mu \mathrm{g}$ de Ru, termicamente reduzido sobre a superfície de plataformas de grafite em atomizadores com aquecimento longitudinal, para determinações de Al em soro sanguíneo e urina.

Em 1998, Borba da Silva et al. avaliaram a modificação permanente da mistura constituída de $\mathrm{Ir}+\mathrm{Rh}$ para determinação de $\mathrm{Ag}$, As, $\mathrm{Bi}, \mathrm{Cd}$ e $\mathrm{Sb}$ em amostras de tecidos de ostras. Posteriormente, os mesmos autores avaliaram em $1999 \mathrm{Ru}$ como modificador permanente, depositado termicamente na plataforma, para determinar $\mathrm{Ag}, \mathrm{Pb}$ e $\mathrm{Sn}$ em extratos de água régia, obtendo em média 1700 ciclos de aquecimento. As temperaturas de pirólise e de atomização para chumbo, foram respectivamente, 800 e $1700^{\circ} \mathrm{C}$.

Em 2002, Meeravali et al. propuseram um revestimento constituído de $200 \mu \mathrm{g} Z \mathrm{r}+20 \mu \mathrm{g}$ Ir para determinação de Sn em suspensões de sedimentos e tecido de ostra, obtendo em média 550 ciclos de aquecimento.

Patricia \& Campos em 2000 propuseram, como modificador, $600 \mu \mathrm{g}$ de Ir reduzido termicamente sobre a superfície da plataforma grafitica, para determinação direta de chumbo em sangue, obtendo mais de 1100 ciclos de aquecimento. 
Em 1999, Slaveykova et al. obtiveram informações importantes a respeito da distribuição do irídio como modificador permanente sobre plataformas grafíticas. Utilizando as técnicas de microscopia eletrônica de varredura (SEM), espectroscopia fotoelétrica de raio-X (XPS) e fluorescência de raios-X (XRF) verificaram o efeito do tratamento térmico na vaporização do $\mathrm{Bi}, \mathrm{Ag}$ e Te. Os autores concluíram que a estabilização térmica do analito pelo modificador dependia, principalmente, das interações analito-modificador, analito-grafite e modificador-grafite, onde a perda do analito por volatilização durante a etapa de pirólise era determinada pela interação analito-modificador. 


\section{MATERIAL E MÉTODOS}

\subsection{Descontaminação dos materiais e armazenagem das soluções}

O material plástico e as vidrarias foram limpos imergindo-os em banho $10 \% \mathrm{v} / \mathrm{v} \mathrm{HNO}_{3}$ por $24 \mathrm{~h}$ sendo posteriormente enxaguados 4 vezes com água desionizada. O material descontaminado foi seco em capela de fluxo laminar horizontal, (VECO - Brasil), equipada com filtro HEPA e instalada em sala limpa, na qual o ar é constantemente recirculado passando por um sistema de filtração externo. Esse sistema permite que a pressão interna da sala permaneça positiva, limitando a entrada de partículas no interior da sala. A sala limpa contém:

a) oito entradas de ar com fluxo laminar vertical, localizadas no teto, que insuflam ar através de filtros HEPA de 60 × $60 \mathrm{~cm}$ (TROX),

b) uma capela com fluxo laminar horizontal (VECO), onde é realizada a secagem, do material descontaminado,

c) duas capelas de exaustão (VIDY) para preparo de soluções, e purificação de ácido nítrico e clorídrico.

Os copos do amostrador e as ponteiras de micropipetas foram descontaminados de maneira similar. Todas as soluções foram armazenadas em frascos de polipropileno (Nalgene ${ }^{\circledR}$ ) Cat. No. 1717V29. 


\subsection{Reagentes e soluções}

Água destilada-desionizada purificada (resistividade de $18 \mathrm{M} \Omega \mathrm{cm}^{-1}$ ) em sistema Milli-Q ${ }^{\circledR}$ (Millipore, Bedford, MA, USA) foi utilizada em todos os experimentos.

O ácido nítrico utililizado para o preparo das soluções foi destilado a temperatura inferior à da ebulição (sub-ebulição) através de destilador de quartzo (Kürner Analysentechnik, Alemanha).

As soluções de trabalho foram preparadas em meio $0,2 \%$ v/v $\mathrm{HNO}_{3}$ a partir de diluições adequadas da solução estoque $1000 \mathrm{mg} \mathrm{l}^{-1} \mathrm{~Pb}$. Curvas analíticas de calibração foram preparadas entre 0,0 e $20,0 \mu \mathrm{g} \mathrm{I}^{-1}$ de $\mathrm{Pb}$ por sucessivas diluições da solução estoque.

Uma solução estoque de ródio de $1,0 \mathrm{~g}^{-1}$ foi preparada dissolvendo-se 0,020 $\mathrm{g} \mathrm{RhCl}_{3}$ (Sigma) em 10,0 ml de 2,0 \% v/v $\mathrm{HNO}_{3}$.

Uma solução estoque de tungstênio de $1,0 \mathrm{~g}^{-1}$ foi preparada dissolvendo-se $0,1794 \mathrm{~g}$ de $\mathrm{Na}_{2} \mathrm{WO}_{4} \cdot 2 \mathrm{H}_{2} \mathrm{O}$ (Merck) em $100 \mathrm{ml}$ de água desionizada.

O modificador químico convencional 0,05\% m/v Pd +0,03\% m/v $\mathrm{Mg}\left(\mathrm{NO}_{3}\right)_{2}$ foi preparado por diluição a partir de uma solução de $\mathrm{PdCl}_{3}$ (Merck) contendo $10,0 \mathrm{~g} \mathrm{I}^{-1} \mathrm{Pd}$ e de uma solução $10,0 \mathrm{~g} \mathrm{I^{-1 }} \mathrm{Mg}\left(\mathrm{NO}_{3}\right)_{2}$ (Merck). 


\subsection{Instrumentação}

Utilizou-se um espectrômetro de absorção atômica Varian SpectrAA-220, com corretor de absorção de fundo com lâmpada de deutério e equipado com forno de grafite GTA 110. Foram empregados, tubos de grafite pirolítico (Part $n^{\circ}$ 6310001200), plataforma pirolítica (Part $n^{\circ}$ 6310001300), tubo de grafite pirolítico com plataforma integrada modelo Universal (Part no 6310002600) e lâmpada de catodo oco de chumbo (Part no 56101248-00) (Varian, Australia).

Todas as medidas foram realizadas em triplicata e baseadas em absorbância integrada (integral da absorbância em função do tempo).

Como gás de proteção foi usado o argônio (99,95\% de pureza).

Para pesagem das amostras utilizou-se balança Mettler modelo AE 100 (Greifensee, Suiça).

\subsection{Amostras de açúcar}

Foram coletadas amostras de açúcar cristal (denominação genérica de todos os açúcares em forma cristalina produzidos diretamente em usina de açúcar), de usinas localizadas nas regiões de Ribeirão Preto, Quatá, Piracicaba e nos Estados do Paraná, Minas Gerais, Mato Grosso do Sul e Góias. Foram também adquiridas no comercio local amostras de açúcar refinado, açúcar demerara ou bruto (apresenta coloração escura e é levemente mais úmido pois conserva uma película de mel em volta dos cristais de sacarose), e açúcar orgânico (produzido sem qualquer fertilizante químico na fase agrícola). As amostras foram armazenadas em sacos plásticos e guardadas em prateleiras no laboratório, protegidas da luz e umidade. 


\subsection{Preparação das amostras de açúcar}

As amostras de açúcar foram homogeneizadas na própria embalagem. Pesaram-se exatamente $4 \mathrm{~g}$ de açúcar, e transferiu-se a sub-amostra para balão volumétrico de $50 \mathrm{ml}$. Adicionou-se $0,1 \mathrm{ml}$ de $\mathrm{HNO}_{3}$ concentrado purificado em cada balão volumétrico e completou-se o volume com água desionizada. As amostras foram dissolvidas por agitação manual e armazenadas em frascos de polipropileno (Nalgene ${ }^{\circledR}$ ).

Alíquotas de $10 \mu \mathrm{l}$ das soluções de açúcar foram introduzidas no tubo de grafite através do amostrador automático do próprio espectrômetro.

\subsection{Revestimento da superfície grafítica}

O revestimento da superfície grafítica foi feito de acordo o procedimento descrito por Lima et al. (1998), depositando-se inicialmente $250 \mu \mathrm{g} \mathrm{W}$, seguindo-se o revestimento com $200 \mu \mathrm{g} \mathrm{Rh}$.

\section{Revestimento com tungstênio}

Etapa 1: $50 \mu \mathrm{l}$ de solução 1,0 $\mathrm{g}^{-1}$ tungstênio foram depositados sobre a plataforma grafítica.

Etapa 2: Executou-se o seguinte programa de aquecimento (rampa, patamar) para secagem e pirólise: $120^{\circ} \mathrm{C}(5 \mathrm{~s}, 25 \mathrm{~s}), 150^{\circ} \mathrm{C}$ (10s, 60s), $600^{\circ} \mathrm{C}(20 \mathrm{~s}, 15 \mathrm{~s}), 1000^{\circ} \mathrm{C}(10 \mathrm{~s}, 15 \mathrm{~s})$.

Etapa 3: As etapas 1 e 2 foram repetidas por três vezes.

Etapa 4: Repetiu-se a etapa 1 e executou-se o seguinte programa de aquecimento (rampa, patamar): $120^{\circ} \mathrm{C}(5 \mathrm{~s}, 25 \mathrm{~s}), 150^{\circ} \mathrm{C}$ 
(10s, $60 \mathrm{~s}), 600^{\circ} \mathrm{C}(20 \mathrm{~s}, 15 \mathrm{~s}), 1000^{\circ} \mathrm{C}(10 \mathrm{~s}, 15 \mathrm{~s}), 1400^{\circ} \mathrm{C}(10 \mathrm{~s}, 5 \mathrm{~s}), 2000^{\circ} \mathrm{C}$ $(3 s, 2 s)$.

Etapa 5: Executou-se quatro vezes o programa de aquecimento para condicionamento do carbeto de tungstênio em temperaturas mais baixas: $150^{\circ} \mathrm{C}(1 \mathrm{~s}, 10 \mathrm{~s}), 600^{\circ} \mathrm{C}(10 \mathrm{~s}, 15 \mathrm{~s}), 1100^{\circ} \mathrm{C}(10 \mathrm{~s}, 5 \mathrm{~s}), 1400^{\circ} \mathrm{C}$ (10s, 10s).

Etapa 6: Executou-se quatro vezes o programa de aquecimento para condicionamento do carbeto de tungstênio em temperaturas mais elevadas: $150^{\circ} \mathrm{C}(1 \mathrm{~s}, 10 \mathrm{~s}), 600^{\circ} \mathrm{C}(10 \mathrm{~s}, 15 \mathrm{~s}), 1100^{\circ} \mathrm{C}(10 \mathrm{~s}, 5 \mathrm{~s}), 1400^{\circ} \mathrm{C}$ $(10 \mathrm{~s}, 10 \mathrm{~s}), 1500^{\circ} \mathrm{C}(3 \mathrm{~s}, 5 \mathrm{~s}), 1600^{\circ} \mathrm{C}(1 \mathrm{~s}, 1 \mathrm{~s}), 1700^{\circ} \mathrm{C}(1 \mathrm{~s}, 1 \mathrm{~s}), 1800^{\circ} \mathrm{C}(1 \mathrm{~s}$, $1 \mathrm{~s}), 1900^{\circ} \mathrm{C}(1 \mathrm{~s}, 1 \mathrm{~s}), 2000^{\circ} \mathrm{C}(1 \mathrm{~s}, 1 \mathrm{~s})$.

\section{Revestimento com ródio}

Etapa 7: $50 \mu \mathrm{l}$ de solução $1,0 \mathrm{~g} \mathrm{I}^{-1}$ ródio foram depositadas sobre a plataforma grafitica.

Etapa 8: Executou-se o seguinte programa de aquecimento (rampa, patamar) para secagem e pirólise: $120^{\circ} \mathrm{C}(1 \mathrm{~s}, 25 \mathrm{~s}), 150^{\circ} \mathrm{C}$ (5s, 60s), $1000^{\circ} \mathrm{C}(10 \mathrm{~s}, 10 \mathrm{~s}), 1400^{\circ} \mathrm{C}(1 \mathrm{~s}, 5 \mathrm{~s})$.

Etapa 9: As etapas 7 e 8 foram repetidas por mais 3 vezes.

Etapa 10: Repetiu-se a etapa 7 e executou-se o seguinte programa de aquecimento (rampa, patamar): $120^{\circ} \mathrm{C}(1 \mathrm{~s}, 25 \mathrm{~s}), 150^{\circ} \mathrm{C}$ (5s, 60s), $1000^{\circ} \mathrm{C}(10 \mathrm{~s}, 10 \mathrm{~s}), 1400^{\circ} \mathrm{C}(1 \mathrm{~s}, 5 \mathrm{~s}), 2000^{\circ} \mathrm{C}(1 \mathrm{~s}, 3 \mathrm{~s})$. 


\section{PROCEDIMENTO EXPERIMENTAL}

Foram obtidas curvas de temperatura de pirólise e de atomização na ausência e presença da modificação permanente com $250 \mu \mathrm{g}$ de $\mathrm{W}+200 \mu \mathrm{g}$ de Rh e também da modificação convencional com a mistura de $0,05 \%$ de $\mathrm{Pd}+0,03 \% \mathrm{Mg}\left(\mathrm{NO}_{3}\right)_{2}$.

\subsection{Curvas de temperatura de pirólise}

As curvas de temperatura de pirólise com e sem modificador foram obtidas com os resultados das medidas de absorbância após injeção de $10 \mu \mathrm{l}$ da solução de açúcar $8 \% \mathrm{~m} / \mathrm{v}$ em 0,2 \% v/v $\mathrm{HNO}_{3}$ $50 \mu \mathrm{g} \mathrm{I}^{-1} \mathrm{~Pb}$. Para tanto fixou-se a temperatura de atomização $\left(1800^{\circ} \mathrm{C}\right.$ - recomendada pelo fabricante) e variou-se a temperatura de pirólise. A Tabela 7 apresenta o programa de aquecimento utilizado. As temperaturas das etapas 5, 6, e 7 correspondentes à etapa de pirólise, foram variadas com incrementos de $100^{\circ} \mathrm{C}$ a partir de $400^{\circ} \mathrm{C}$ até a diminuição do sinal. 
Tabela 7. Programa de aquecimento utilizado para atomização de chumbo, e obtenção da curva de temperatura de pirólise

\begin{tabular}{cccc}
\hline Etapa & Temperatura $\left({ }^{\circ} \mathrm{C}\right)$ & Rampa $(\mathrm{s})$ & Vazão de argônio $\left(\mathrm{I} \mathrm{min}^{-1}\right)$ \\
\hline 1 & 120 & 5 & 3 \\
2 & 120 & 10 & 3 \\
3 & 150 & 5 & 3 \\
4 & 150 & 10 & 3 \\
5 & $*$ & 10 & 3 \\
6 & $*$ & 20 & 3 \\
7 & $*$ & 2 & 0 \\
8 & 1800 & 0,5 & 0 \\
9 & 1800 & 5 & 0 \\
10 & 2400 & 1 & 3 \\
\hline
\end{tabular}

* temperaturas de 400 a $1300^{\circ} \mathrm{C}$

\subsection{Curvas de temperatura de atomização}

As curvas de temperatura de atomização com e sem modificador foram obtidas com os resultados das medidas de absorbância após injeção de $10 \mu \mathrm{l}$ da solução de açúcar $8 \% \mathrm{~m} / \mathrm{v}$ em $0,2 \% \mathrm{v} / \mathrm{v} \mathrm{HNO}_{3} 50 \mu \mathrm{g} \mathrm{I}^{-1} \mathrm{~Pb}$. Para tanto fixou-se a temperatura de pirólise (obtida no item 4.1) e variou-se a temperatura de atomização. A Tabela 7 apresenta o programa de temperatura utilizado. As temperaturas das 
etapas 8 e 9, correspondentes a temperatura de atomização, foram variadas com incrementos de $100^{\circ} \mathrm{C}$ a partir de $1300^{\circ} \mathrm{C}$.

\subsection{Limites de detecção}

Os limites de detecção foram calculados a partir do desvio padrão de 20 medidas do branco analítico (solução $8 \%$ m/v de açúcar em $0,2 \% \mathrm{v} / \mathrm{v} \mathrm{HNO}_{3}$ ) de acordo a equação 3s/a, onde s é a estimativa do desvio padrão e a é o coeficiente angular da curva de calibração. A massa característica foi determinada a partir da curva de calibração. 


\title{
5 RESULTADOS E DISCUSSÃO
}

\subsection{Programas de aquecimento para determinação de chumbo em soluções de açúcar}

\begin{abstract}
A modificação química permanente em atomizadores de grafite tornou-se um meio importante para modificação química em GFAAS. Para modificação permanente em determinações por GFAAS (e.g. As, $\mathrm{Cd}, \mathrm{Hg}, \mathrm{Pb}, \mathrm{Se}$ ), espera-se a estabilização térmica de vários analitos em temperaturas de pirólise elevadas, assim como uma maior taxa de amostragem, uma vez que programas de aquecimento mais rápidos podem ser empregados para amostras complexas. Porém, a modificação permanente apresenta alguns inconvenientes, quando comparada com a modificação química convencional, como menor interação do analito em matrizes complexas com a superfície grafítica modificada, bem como uma menor ação de modificador químico sobre os concomitantes.

Neste trabalho, inicialmente, foram avaliados diferentes programas de aquecimento com $250 \mu \mathrm{g} \mathrm{W}+200 \mu \mathrm{g} R \mathrm{Rh}$ depositados termicamente sobre a plataforma grafítica adaptada ao tubo de grafite. Essa plataforma foi escolhida face à facilidade de introdução no forno de grafite, e devido à maior facilidade de inspeção visual na formação de resíduos carbonáceos. Para estas avaliações, foi escolhido o programa de aquecimento descrito por Lima et al. (1998) para determinação direta
\end{abstract}


de chumbo em matrizes com alto teor de açúcar (Tabela 5). Curvas de temperatura de pirólise e atomização (Figura 2) foram traçadas a partir dos dados obtidos com injeção de $10 \mu \mathrm{l}$ de solução de açúcar $8 \% \mathrm{~m} / \mathrm{v}$ em $0,2 \% \mathrm{v} / \mathrm{v} \mathrm{HNO}_{3}$ contendo $50 \mu \mathrm{g} \mathrm{I}^{-1} \mathrm{~Pb}$ sobre a plataforma grafítica revestida termicamente com $250 \mu \mathrm{g} \mathrm{W}+200 \mu \mathrm{g} \mathrm{W}$.

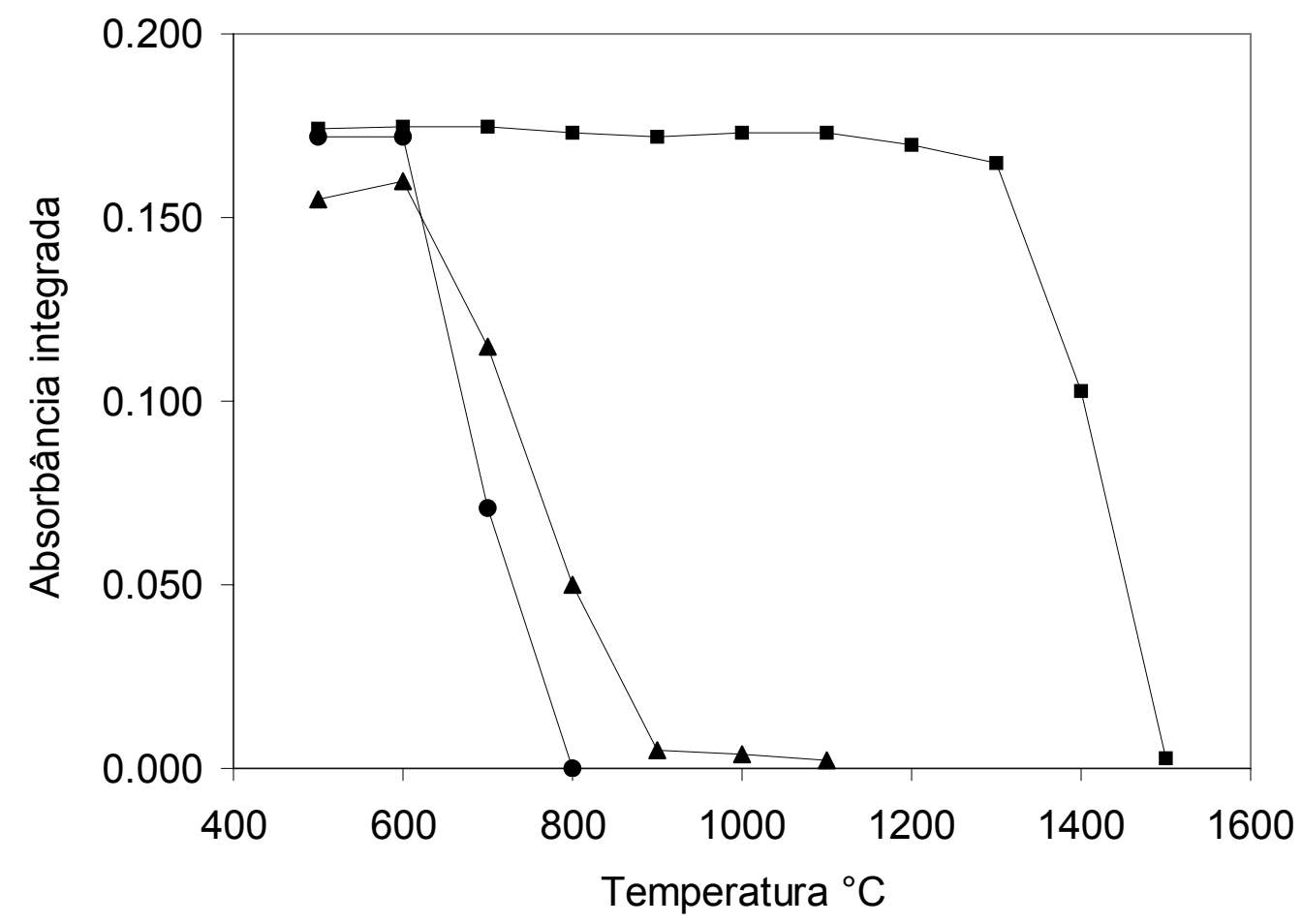

Figura 2. Curvas de temperatura de pirólise $\left(T_{\text {atomização }}=1800^{\circ} \mathrm{C}\right)$ para $10 \mu \mathrm{l}$ de solução $50 \mu \mathrm{g} \mathrm{I}^{-1} \mathrm{~Pb}$ em solução $8 \% \mathrm{~m} / \mathrm{v}$ açúcar em $0,2 \% \mathrm{v} / \mathrm{v} \mathrm{HNO}_{3}$. Plataforma revestida com $250 \mu \mathrm{g} \mathrm{W}+200 \mu \mathrm{g}$ Rh. (•) Sem injeção de Rh. (•) Com injeção de $5 \mu \mathrm{g}$ Rh. (ム) Plataforma sem revestimento

Os resultados observados indicam que não houve estabilização térmica de chumbo em presença de açúcar em temperaturas de pirólise 
superiores a $600^{\circ} \mathrm{C}$. A baixa estabilidade térmica do chumbo pode, possivelmente, ser explicada devido ao alto teor de matéria orgânica presente na solução, a qual pode diminuir a interação do analito com o modificador permanente depositado na plataforma grafítica. Zanão et al. (2002) mostraram que a co-injeção de Rh em solução foi necessária para promover a estabilização térmica de Se na etapa de pirólise para determinar Se em sangue por ETAAS, utilizando plataformas recobertas com W-Rh depositados termicamente.

Assim foram avaliadas curvas de temperatura de pirólise com a injeção de $5 \mu \mathrm{g}$ de Rh ( $5 \mu \mathrm{l}$ de $\left.1000 \mathrm{mg} \mathrm{l}^{-1}\right)$ em $10 \mu \mathrm{l}$ da solução de açúcar sobre a superfície da plataforma revestida com $250 \mu \mathrm{g} \mathrm{W}+200 \mu \mathrm{g}$ Rh. Para temperaturas de pirólise de $600^{\circ} \mathrm{C}$ observou-se formação de resíduos carbonáceos sobre a plataforma grafítica. A temperatura máxima de pirólise obtida para estabilização de chumbo com injeção de $\mathrm{Rh}$ foi de, aproximadamente, $1300^{\circ} \mathrm{C}$.

Para remoção do resíduo carbonáceo, geralmente formado durante a etapa de pirólise, alguns trabalhos sugerem que a pirólise seja assistida por oxigênio (Miller-ilhi,1994) ou que a decomposição seja feita utilizando-se peróxido de hidrogênio $\left(\mathrm{H}_{2} \mathrm{O}_{2}\right)$ antes da determinação dos analitos. (Viñas et al. 1997), Dakukazu et al. (2001) utilizou a pirólise assistida por oxigênio para evitar a formação de resíduos carbonáceos na etapa de pirólise para determinar As em açúcar. Contudo, a utilização desse método pode diminuir a vida útil do forno de grafite.

Uma vez que o objetivo deste trabalho foi à determinação direta de chumbo em soluções de açúcar, sem diminuir a vida útil dos tubos de grafite, optou-se por evitar etapas de decomposição da amostra ou etapas de pirólise assistidas por oxigênio. Programas de aquecimento 
com uma etapa de pré-pirólise para eliminação do resíduo carbonáceo sobre a superfície da plataforma móvel foram avaliados (Tabela 8).

Tabela 8. Programa de aquecimento utilizado para avaliação da formação de resíduos carbonáceos sobre plataforma móvel revestida termicamente com $250 \mu \mathrm{g} \mathrm{W}+200 \mu \mathrm{g}$ Rh e co-injeção de $5 \mu \mathrm{g}$ Rh em solução

\begin{tabular}{ccccc}
\hline Etapas & $\begin{array}{c}\text { Temperatura } \\
\left({ }^{\circ} \mathrm{C}\right)\end{array}$ & $\begin{array}{c}\text { Rampa } \\
(\mathrm{s})\end{array}$ & $\begin{array}{c}\text { Patamar } \\
(\mathrm{s})\end{array}$ & $\begin{array}{c}\text { Vazão de argônio } \\
\left(\mathrm{I} \mathrm{min}^{-1}\right)\end{array}$ \\
\hline Secagem & 150 & 5 & 25 & 3 \\
Secagem & 180 & 5 & 25 & 3 \\
Pirólise & 700 & $10-50$ & 5 & 3 \\
Pirólise & 1100 & 5 & 10 & 3 \\
Pirólise & 1100 & 2 & 2 & 0 \\
Atomização & 1800 & 0,4 & 5 & 0 \\
Limpeza & 2400 & 1 & 4 & 3 \\
\hline
\end{tabular}

Os experimentos foram conduzidos variando-se o tempo de prépirólise entre 10 , e $50 \mathrm{~s}$, fixando-se a temperatura de pré-pirólise em $700^{\circ} \mathrm{C}$, utilizando-se $10 \mu \mathrm{l}$ da solução de $8 \% \mathrm{~m} / \mathrm{v}$ de açúcar em 0,2 \% v/v $\mathrm{HNO}_{3}$ contendo $50 \mu \mathrm{g} \mathrm{I}^{-1} \mathrm{~Pb}$. As plataformas móveis eram retiradas do tubo a cada 50 queimas para inspeção visual sobre a formação de resíduos carbonáceos. Os resultados obtidos indicaram que, para 50s de pirólise a $700^{\circ} \mathrm{C}$, foi possível reduzir a formação de resíduos carbonáceos (Figuras 3 A-D) 
(A)

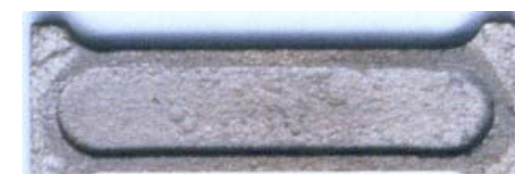

(C)

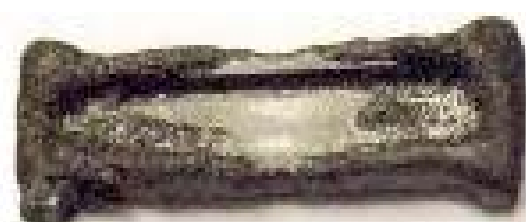

(B)

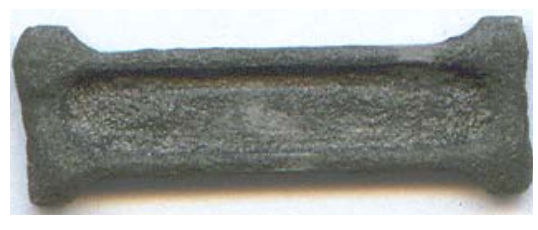

(D)

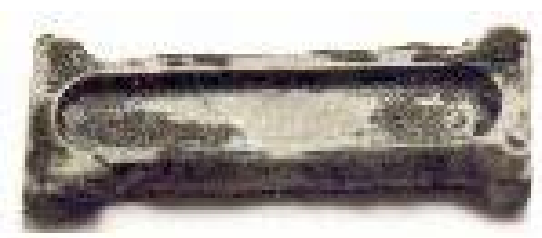

Figura 3. Plataformas grafíticas revestidas termicamente com $250 \mu \mathrm{g} \mathrm{W}+200 \mu \mathrm{g}$ Rh e co-injeção de $5 \mu \mathrm{g}$ Rh. (A) plataforma nova; (B) após 150 ciclos de aquecimento e pirólise a $700^{\circ} \mathrm{C}$ durante 10s; (C) após 300 ciclos de aquecimento e pirólise a $700^{\circ} \mathrm{C}$ durante $35 \mathrm{~s}$; (D) após 450 ciclos de aquecimento e pirólise a $700^{\circ} \mathrm{C}$ durante $50 \mathrm{~s}$

Os tubos de grafite com plataformas móveis adaptadas manualmente foram eficientemente utilizados para a avaliação da formação de resíduos carbonáceos. Entretanto, observou-se que essas plataformas se deslocam dentro do tubo durante a etapa de atomização, mudando facilmente de posição. Esses efeitos ocasionaram variações das medidas em absorbância. A Figura 4 mostra as variações das medidas de absorbância durante os 450 ciclos de aquecimento. Cada ponto representa a média de 10 medidas consecutivas com a respectiva incerteza, representada por barra, e equivalente a 1 desvio-padrão. 


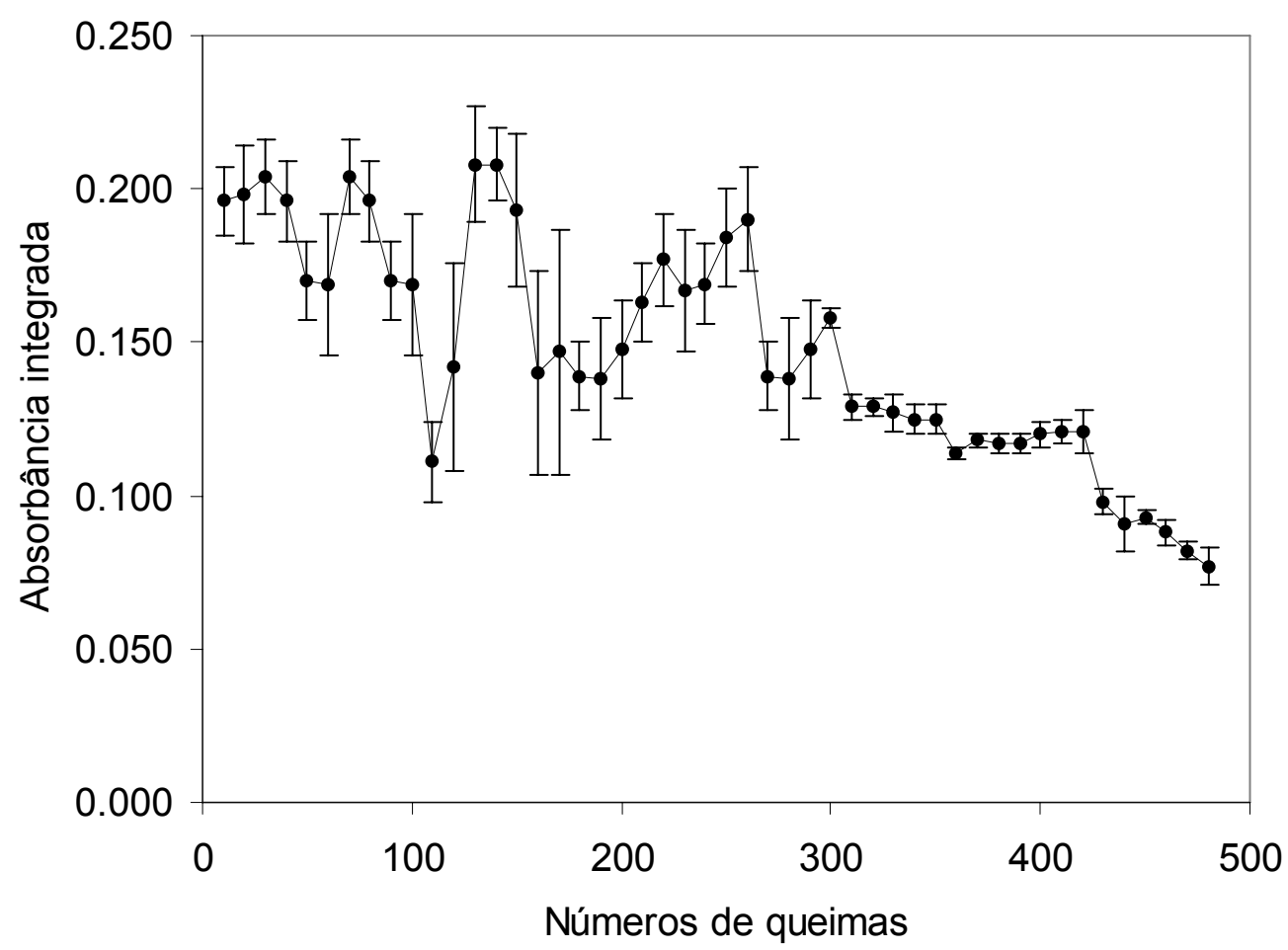

Figura 4. Variações das medidas de absorbância observadas na utilização da plataforma grafítica móvel revestida termicamente com $250 \mu \mathrm{g} \mathrm{W}+200 \mu \mathrm{g}$ Rh durante 450 ciclos de aquecimento. Cada ponto representa a média de 10 medidas consecutivas

Observam-se incertezas que, levavam a coeficientes de variação maiores que $80 \%$ para as primeiras 300 medidas.

Em face a este inconveniente utilizaram-se apenas tubos de grafite modelo Universal (Varian). No restante do trabalho curvas de temperatura de pirólise e de atomização utilizando $10 \mu \mathrm{l}$ da solução de $8 \% \mathrm{~m} / \mathrm{v}$ de açúcar em0,2 \% v/v $\mathrm{HNO}_{3}$ contendo $50 \mu \mathrm{g} \mathrm{l}{ }^{-1} \mathrm{~Pb}$ foram avaliadas com modificador convencional $(\mathrm{Pd}+\mathrm{Mg})$, e com a modificação permanente $(\mathrm{W}+\mathrm{Rh})$ e co-injeção de Rh. Observou-se que a temperatura 
de pirólise com o modificador permanente $(\mathrm{W}+\mathrm{Rh})$ foi $100^{\circ} \mathrm{C}$ superior ao modificador convencional $(\mathrm{Pd}+\mathrm{Mg})$ e que as melhores temperaturas de atomização para ambos modificadores se situavam entre 1600 e $1700^{\circ} \mathrm{C}$ (Figura 4). Estes valores estão bem próximos das temperaturas de atomização em torno de $1800^{\circ} \mathrm{C}$ utilizadas para determinação de $\mathrm{Pb}$ em amostras de mel, açúcar, xaropes por Miller-ihli \& Greene, (1993), Vinas et al (1997), Lima et al. (1998) e Morris et al. (2000).

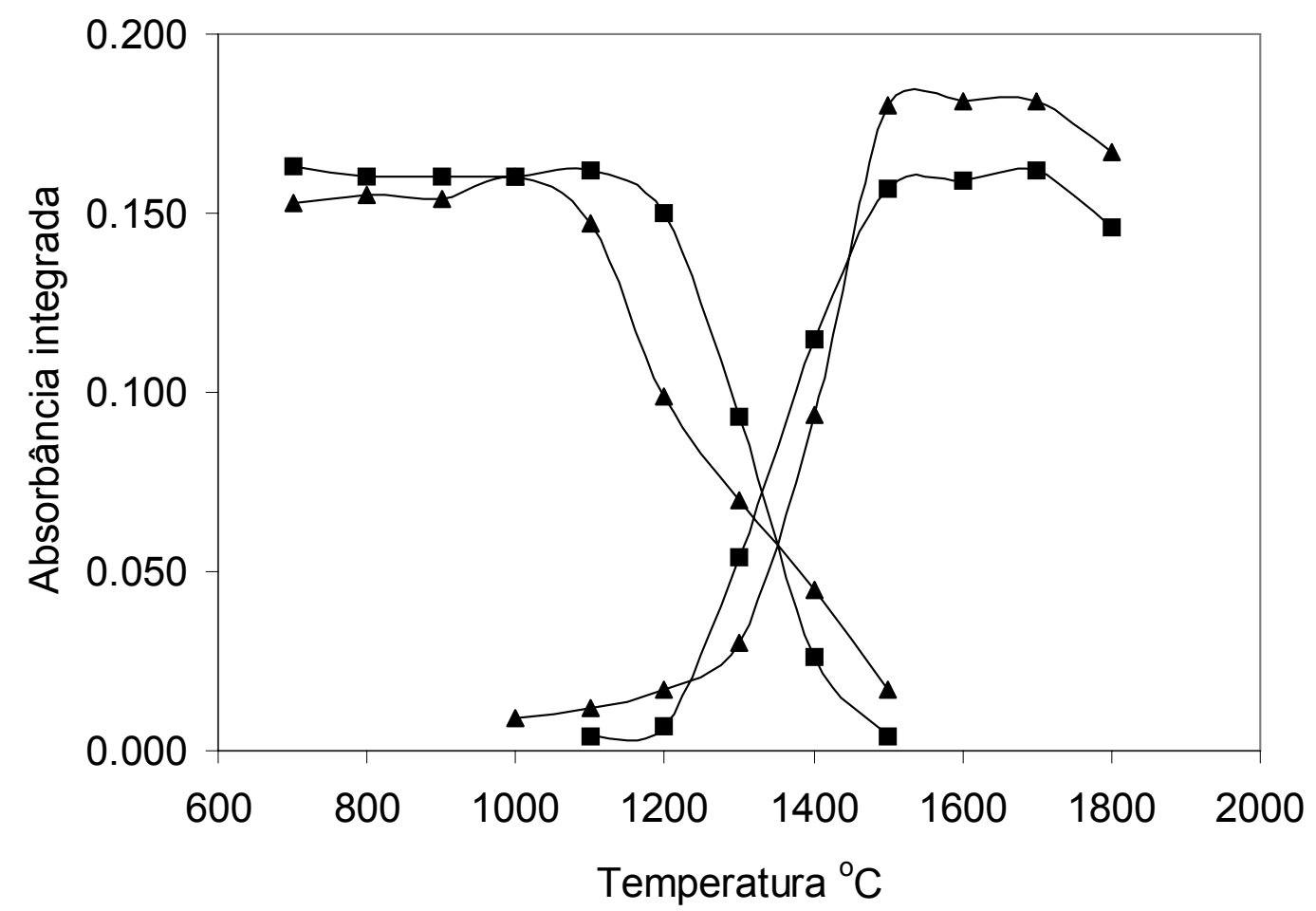

Figura 5. Curvas de temperatura de pirólise $\left(T_{\text {atomização }}=1800^{\circ} \mathrm{C}\right) \mathrm{e}$ atomização $\left(T_{\text {pirólise }}=1000^{\circ} \mathrm{C}\right)$ para $10 \mu \mathrm{l}$ de solução $50 \mu \mathrm{g} \mathrm{I}^{-1}$ $\mathrm{Pb}$ em $0,2 \%$ v/v $\mathrm{HNO}_{3}$ contendo $8 \% \mathrm{~m} / \mathrm{v}$ de açúcar. ( $\mathbf{\Delta}$ ) Adição de $10 \mu \mathrm{l}$ de solução $0,05 \% \mathrm{v} / \mathrm{v} \mathrm{Pd}+0,03 \% \mathrm{v} / \mathrm{v} \mathrm{Mg}\left(\mathrm{NO}_{3}\right)_{2}$ (匹) Modificador permanente $250 \mu \mathrm{g} \mathrm{W}+200 \mu \mathrm{g}$ Rh e co-injeção de $5 \mu \mathrm{g}$ Rh em solução 
A Tabela 9 mostra o programa de aquecimento para determinação direta de chumbo em açúcar,utilizando-se o tubo de grafite modelo Universal com plataforma integrada na presença do modificador químico convencional constituído da mistura de $5 \mu \mathrm{g} \mathrm{Pd}+3 \mu \mathrm{g} \mathrm{Mg}\left(\mathrm{NO}_{3}\right)_{2}$ ou modificação permanente com $250 \mu \mathrm{g} \mathrm{W}+200 \mu \mathrm{g}$ Rh e co-injeção de $5 \mu \mathrm{Rh}$ em solução.

Tabela 9. Programa de aquecimento para determinação direta de chumbo em açúcar utilizando tubo de grafite modelo Universal com plataforma integrada e modificação química convencional ou permanente

\begin{tabular}{ccccc}
\hline Etapa & $\begin{array}{c}\text { Temperatura } \\
\left({ }^{\circ} \mathrm{C}\right)\end{array}$ & $\begin{array}{c}\text { Rampa } \\
(\mathrm{s})\end{array}$ & $\begin{array}{c}\text { Patamar } \\
(\mathrm{s})\end{array}$ & $\begin{array}{c}\text { Vazão de argônio } \\
\left(1 \mathrm{~min}^{-1}\right)\end{array}$ \\
\hline Secagem & 120 & 5 & 10 & 3 \\
Secagem & 150 & 5 & 10 & 3 \\
Pirólise & 700 & 40 & 10 & 3 \\
Pirólise & 1000 & 5 & 10 & 3 \\
Pirólise & 1000 & 2 & 2 & 0 \\
Atomização & 1700 & 0,5 & 5 & 0 \\
Limpeza & 2400 & 1 & 1 & 3 \\
\hline
\end{tabular}

A Figura 6 mostra os sinais de absorção atômica e de fundo (BG) para chumbo com uso da plataforma grafítica integrada, utilizando-se $10 \mu \mathrm{l}$ de solução $50 \mu \mathrm{g} \mathrm{l} \mathrm{I}^{-1} \mathrm{~Pb}$ em solução $8 \% \mathrm{~m} / \mathrm{v}$ de açúcar em $0,2 \% \mathrm{v} / \mathrm{v} \mathrm{HNO}_{3}$. As semelhanças entre os sinais de absorbância do 
analito em soluções aquosas e em soluções com açúcar indicam, possivelmente, que os mecanismos de atomização de chumbo em ambas as soluções são muito semelhantes sugerindo isoformação.

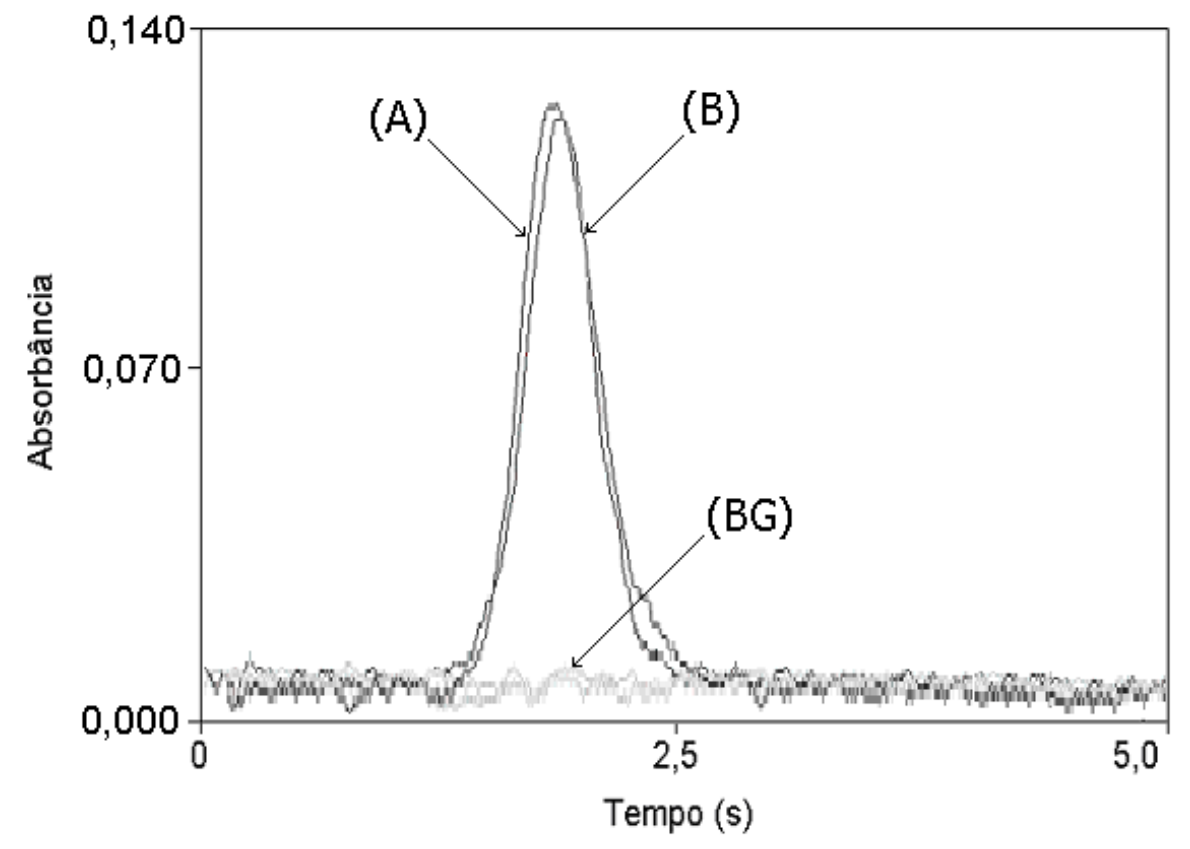

Figura 6. Sinais de absorção atômica e de absorção de fundo (BG) observados para determinação de chumbo com plataforma Universal revestida termicamente com $250 \mu \mathrm{g} \mathrm{W}+200 \mu \mathrm{g}$ Rh e co-injeção de $5 \mu \mathrm{gh}\left(\mathrm{T}_{\text {pirólise }}=1000^{\circ} \mathrm{C} ; \mathrm{T}_{\text {atomização }}=1700^{\circ} \mathrm{C}\right)$.

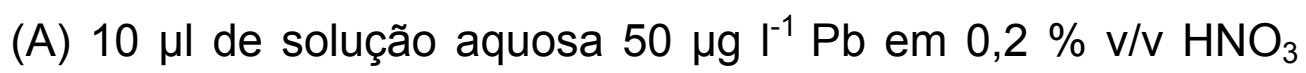
(B) $10 \mu \mathrm{l}$ de solução $8 \% \mathrm{~m} / \mathrm{v}$ de açúcar com $50 \mu \mathrm{g} \mathrm{l^{-1 }} \mathrm{Pb}$ em $0,2 \% \mathrm{v} / \mathrm{v} \mathrm{HNO}_{3}$

Após o estabelecimento dos programas de aquecimento com o uso dos modificadores (Tabela 9), construíram-se curvas analíticas de calibração com os dados obtidos após injeção de $20 \mu \mathrm{l}$ de soluções de referência com $50 \mu \mathrm{g} \mathrm{I}^{-1} \mathrm{~Pb}$ em $0,2 \%$ v/v $\mathrm{HNO}_{3}$ e em solução de açúcar $8 \% \mathrm{~m} / \mathrm{v} 0,2 \% \mathrm{v} / \mathrm{v} \mathrm{HNO}_{3}$. As curvas obtidas (Figura 7) apresentaram 
coeficientes angulares similares para solução aquosa 0,2\% v/v $\mathrm{HNO}_{3}$ $(y=0,0074 X+0,0042, n=3)$ e para solução $8 \% \mathrm{~m} / \mathrm{v}$ de açúcar em $0,2 \%$ $\mathrm{v} / \mathrm{v} \mathrm{HNO}_{3}(\mathrm{y}=0,0075 \mathrm{X}+0,0042, \mathrm{n}=3)$, indicando, possivelmente, que nestas condições, não houve interferência da matriz na atomização de chumbo para o método proposto. Adicionalmente, não foram observadas diferenças significativas na sensibilidade analítica e nos limites de detecção, encontrados utilizando-se o modificador convencional $(\mathrm{Pd}+\mathrm{Mg})$ e o modificador permanente $(\mathrm{W}+\mathrm{Rh})$.

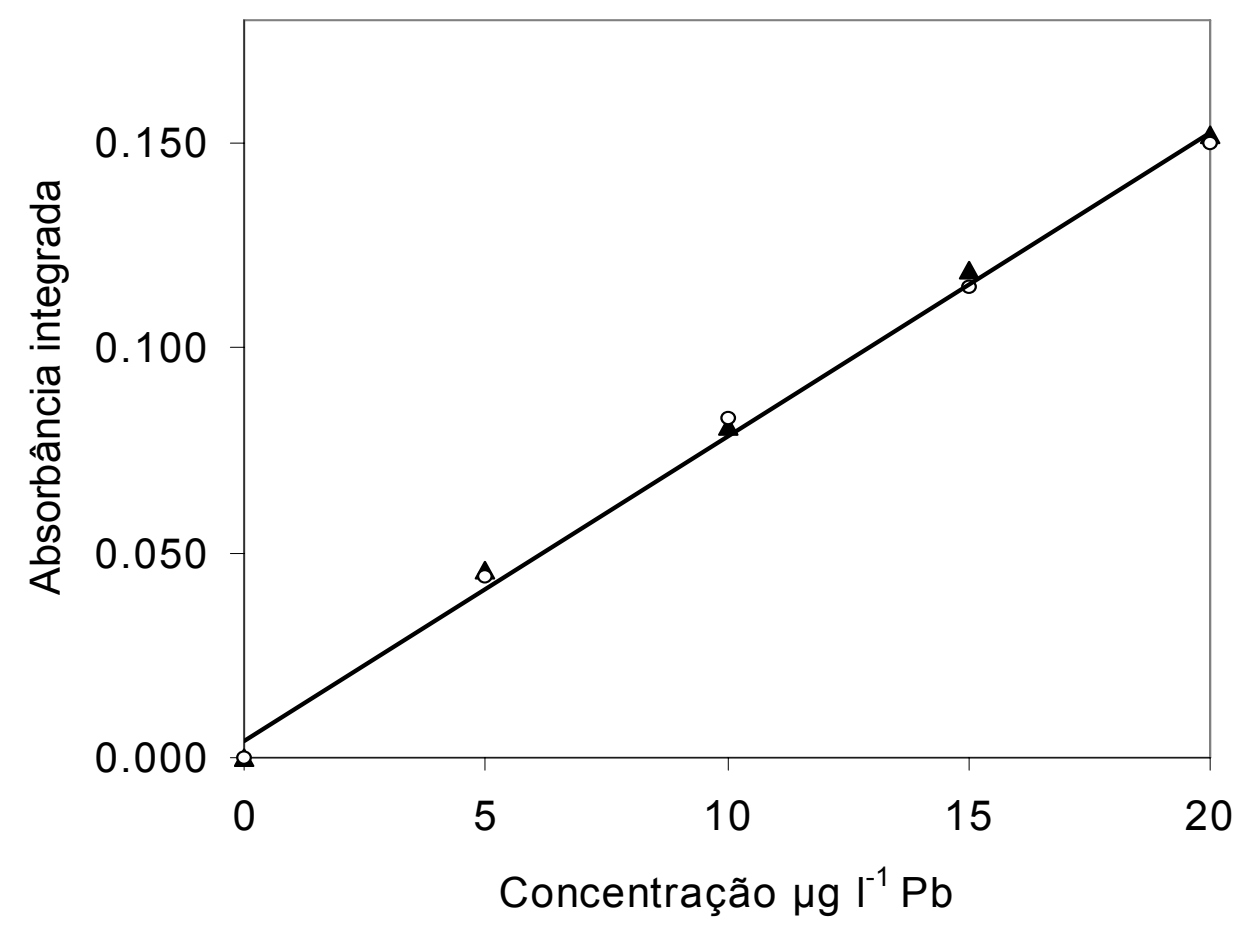

Figura 7. Curvas analíticas de calibração de chumbo utilizando-se Plataforma grafítica com modificador permanente $\mathrm{W}+\mathrm{Rh}$ e coinjeção de $5 \mu \mathrm{g}$ de $\operatorname{Rh}\left(\mathrm{T}_{\text {atomização }}=1700^{\circ} \mathrm{C} ; \mathrm{T}_{\text {pirólise }}=1000^{\circ} \mathrm{C}\right)$. (O) $20 \mu \mathrm{l}$ de solução aquosa $50 \mu \mathrm{gl}^{-1} \mathrm{~Pb}$ em 0,2 \% v/v $\mathrm{HNO}_{3}$ $(r=0,9981)$. (A ) $20 \mu \mathrm{l}$ de solução $8 \% \mathrm{~m} / \mathrm{v}$ de açúcar $50 \mu \mathrm{g} \mathrm{I}^{-1}$ $\mathrm{Pb}$ em $0,2 \% \mathrm{v} / \mathrm{v} \mathrm{HNO}_{3}(r=0,9983)$. 


\subsection{Tempo de vida útil do tubo de grafite}

Foram feitos estudos com tubo de grafite modelo Universal (Varian) com plataforma integrada, utilizando-se tanto o modificador convencional constituído da mistura $\mathrm{Pd}+\mathrm{Mg}$, como o modificador permanente $\mathrm{W}+\mathrm{Rh}$, ambos depositados termicamente. Para tanto, utilizou-se $10 \mu \mathrm{l}$ da solução de açúcar $8 \% \mathrm{~m} / \mathrm{v}$ em $0,2 \%$ v/v de $\mathrm{HNO}_{3}$ contendo $50 \mathrm{\mu g} \mathrm{I}^{-1} \mathrm{~Pb}$. As Figuras 8 e 9) mostram como as medidas de absorbância variam para cada modificador.

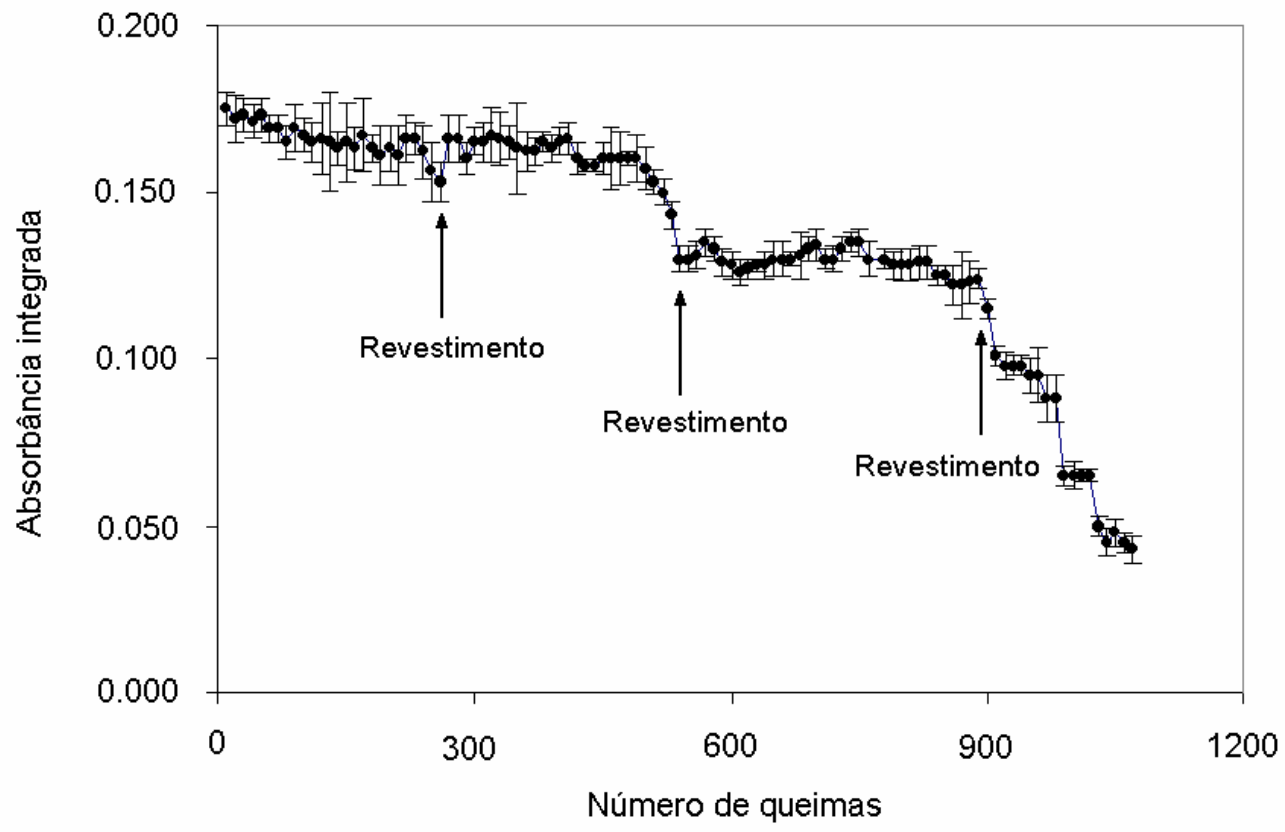

Figura 8. Vida útil do tubo de grafite. Plataforma Universal revestida termicamente com W+Rh e co-injeção de $5 \mu \mathrm{g}$ Rh em cada ciclo de aquecimento. Cada ponto representa a média de 10 leituras de absorbância. Injeção de $10 \mu \mathrm{l}$ de solução $50 \mu \mathrm{g} \mathrm{I}^{-1} \mathrm{~Pb}$ em $8 \% \mathrm{~m} / \mathrm{v}$ de açúcar 


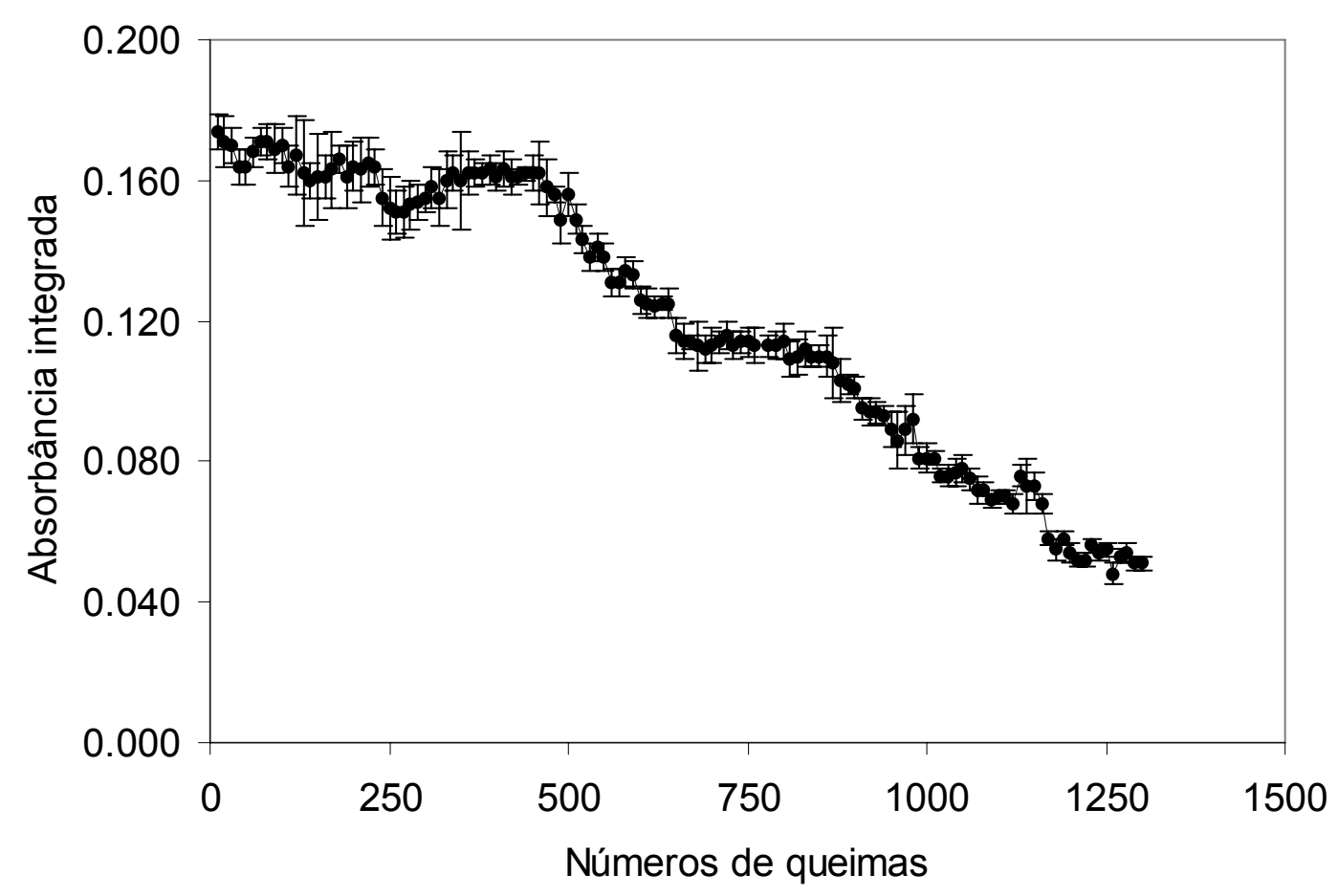

Figura 9. Vida útil do tubo de grafite. Plataforma com adição de $10 \mu \mathrm{l}$ de solução $0,05 \% \mathrm{v} / \mathrm{v} \mathrm{Pd}+0,03 \% \mathrm{v} / \mathrm{v} \mathrm{Mg}\left(\mathrm{NO}_{3}\right)_{2}$. Cada ponto representa a média de 10 leituras de absorbância. Injeção de $10 \mu \mathrm{l}$ de solução $50 \mu \mathrm{g} \mathrm{I}^{-1} \mathrm{~Pb}$ em $8 \% \mathrm{~m} / \mathrm{v}$ de açúcar

Novos revestimentos foram realizados com $\mathrm{W}$ e $\mathrm{Rh}$ durante a utilização do tubo de grafite a cada 250 ciclos de aquecimento. Os resultados obtidos mostram uma queda de $10 \%$ na sensibilidade analítica para ambos modificadores após aproximadamente, 500 ciclos de aquecimentos. Essas perdas de sensibilidade foram devidas ao desgaste na parede do tubo próximo do orifício de amostragem como mostra a Figura 10. Esse desgaste prejudica o ambiente térmico no interior do tubo de grafite, assim como proporciona maior difusão da nuvem atômica, diminuindo, conseqüentemente, a sensibilidade analítica. 
No tubo com revestimento de $\mathrm{W}+\mathrm{Rh}$ após queda pronunciada do sinal, fez-se novo revestimento. As leituras foram relativamente estáveis até 900 queimas, mostrando um comportamento superior ao tratamento com $\mathrm{Pd}+\mathrm{Mg}$ por ser desnecessária recalibração. Quando se utilizou $\mathrm{Pd}+\mathrm{Mg}$ a queda da sensibilidade foi constante. Isto permite inferir que o revestimento com $\mathrm{W}+\mathrm{Rh}$ deva ser recomendado para determinação de chumbo em açúcar, apesar de externamente os tubos terem sofrido desgaste similar. É evidente que a superfície da plataforma tratada com $\mathrm{W}+\mathrm{Rh}$ teve um efeito benéfico na manutenção da sensibilidade durante um, grande número de queimas.

(A)

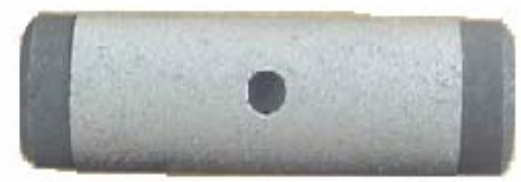

(B)

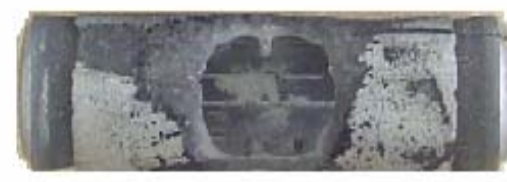

(C)

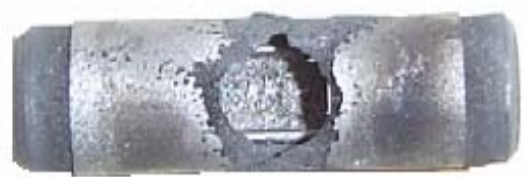

Figura 10. Tubo de grafite modelo Universal com plataforma integrada. (A) Novo. (B) Após 1070 ciclos de aquecimento, utilizando modificação permanente (W+Rh). (C) Após 1300 ciclos de aquecimento, utilizando modificação convencional (Pd+Mg) 


\subsection{Características analíticas}

A massa característica $\left(m_{0}\right)$ do método baseado no uso do modificador permanente W+Rh e co-injeção de $5 \mu \mathrm{g}$ Rh foi de (11 pg Pb), valor semelhante ao obtido com o modificador convencional $\mathrm{Pd}+\mathrm{Mg}$ de (13 pg Pb). Estes valores estão próximos aos obtidos por Miller-ihli, (1994) e por Lima et al. (1998) de 12 e 15 pg Pb, respectivamente. A faixa útil de calibração com soluções analíticas em meio aquoso situou-se entre 0,0 e 20,0 $\mu \mathrm{g} \mathrm{I}^{-1} \mathrm{~Pb}$. O limite de detecção do método, calculado a partir do desvio padrão de 20 medidas do branco foi de $5 \mathrm{ng} \mathrm{g}^{-1}$. Os coeficientes de variação das medidas (CV) foram, geralmente, inferiores a $2,5 \%(n=3)$. A Tabela 10 mostra as figuras de mérito do método proposto e de outros 2 trabalhos publicados sobre determinação de chumbo em açúcar.

Observa-se neste estudo que, independentemente do uso de $\mathrm{W}-\mathrm{Rh}$ depositado termicamente ou do modificador convencional $\mathrm{Pd}+\mathrm{Mg}$, os tubos de grafite modelo Universal da Varian suportaram mais de 1000 queimas. Assim, poderia recomendar os dois modificadores para determinação direta de chumbo em açúcar, mas deve-se lembrar os benefícios do revestimento quanto à manutenção de sensibilidade entre 530 e 850 queimas com W+Rh. Cabe ressaltar que nenhum estudo havia sido realizado com modificação química permanente no tubo de grafite modelo Universal da Varian, até o deposito desta dissertação. Os resultados encontrados são diferentes daqueles obtidos até o momento com tubo de grafite com aquecimento transversal (THGA end-capped) da Perkin Elmer. Em geral, a modificação química permanente leva a um aumento considerável da vida útil do tubo. Este fato foi confirmado ao se realizar o revestimento $\mathrm{W}+\mathrm{Rh}$ e co-injeção de Rh no (THGA end-capped) 
usando o mesmo programa de aquecimento recomendado por (Lima et al, 1998) como mostra a Tabela 10. Desempenho semelhantes foram observados nos valores obtidos para os limites de detecção do método e massa característica $\left(\mathrm{m}_{\circ}\right)$ 5,0 $\mathrm{ng} \mathrm{g}^{-1}$ e $11 \mathrm{pg}$ de $\mathrm{Pb}$ respectivamente. No entanto, nenhum ganho em sensibilidade foi observado como mostra a Figura 6.

Tabela 10. Figuras analíticas de mérito entre métodos para determinação direta de chumbo em amostras de açúcar

\begin{tabular}{lccc}
\hline Características analíticas & Miller-lhli (1993) & Lima et al.(1998) & $\begin{array}{c}\text { Método } \\
\text { proposto }\end{array}$ \\
\hline Massa característica $(\mathrm{pg})$ & 12 & 15 & 11 \\
Limite de detecção $\left(\mathrm{ng} \mathrm{g}^{-1}\right)$ & 0,9 & 7,0 & 5,0 \\
Programa de aquecimento $(\mathrm{s})$ & 211 & 105 & 117 \\
Temperatura de pirólise $\left({ }^{\circ} \mathrm{C}\right)$ & 750 & 1000 & 1000 \\
Temperatura de atomização $\left({ }^{\circ} \mathrm{C}\right)$ & 1800 & 1800 & 1700 \\
Correção de fundo & Zeeman & Zeeman & Deutério $\left(\mathrm{D}_{2}\right)$ \\
Vida útil do tubo $\left(\mathrm{n}^{\circ}\right.$ de queimas) & $100^{*}$ & 260 & 850 \\
\hline
\end{tabular}

* pirólise assistida por oxigênio

Em 2002, Zhou et al. utilizaram uma mistura contendo $250 \mu \mathrm{g}$ de $W+200 \mu \mathrm{g}$ de $\mathrm{Rh}$ depositados termicamente no tubo de grafite para determinação de chumbo em sangue. Os autores realizaram 1030 queimas com o tubo de grafite THGA end-capped, e com a modificação convencional de $\mathrm{NH}_{4} \mathrm{H}_{2} \mathrm{PO}_{4}$ apenas 350 ciclos de aquecimento. $\mathrm{O}$ aumento da vida útil do tubo de grafite foi superior a $100 \%$. Neste sentido, experimentos foram conduzidos nesse trabalho, depositando termicamente $250 \mu \mathrm{g}$ de $W+200 \mu \mathrm{g}$ de $\mathrm{Rh}$ em tubo de grafite 
(THGA end-capped) para verificar a possibilidade de prolongamento da vida útil do atomizador e comparar com o número de queimas obtidas através do método proposto por Lima et al. (1998). Observações realizadas nesse trabalho, como mostra a Figura 2 indicam que o $\mathrm{Pb}$ não é estabilizado termicamente em temperaturas superiores a $600^{\circ} \mathrm{C} \mathrm{em}$ virtude da pouca interação entre modificador depositado na superfície grafítica e solução de açúcar. Em função disso foi necessário co-injetar 5 $\mu \mathrm{g}$ de Rh em solução para estabilização de chumbo na etapa de pirólise. Aplicou-se o programa de aquecimento proposto por Lima et al. (1998) e se observou um aumento de no mínimo, 43\% na vida útil do tubo de grafite com CV < 5\% $(n=3)$ em relação á modificação convencional de $\mathrm{Pd}+\mathrm{Mg}$. Infelizmente não foi possível concluir o experimento por problemas técnicos com os equipamentos do CENA-UNESP-Araraquara. Esse aumento é uma boa indicação de que o revestimento da plataforma com $\mathrm{W}+\mathrm{Rh}$ deve ser recomendado também para o THGA.

Comparando-se os custos analíticos entre os procedimentos com modificação permanente de W+Rh e co-injeção de Rh e modificação convencional $(\mathrm{Pd}+\mathrm{Mg})$, proposto por Lima et al. (1998) para determinar chumbo em açúcar, 12 tubos de grafite modelo Universal da Varian e 40 tubos de grafite (THGA end-capped) da Perkin-Elmer seriam consumidos e considerando-se $8 \mathrm{~h}$ de trabalhos diários, 200 dias de trabalho/ano e realizando, em média, 200 determinações/dia. Assim, caso fosse feitas 40000 determinações/ano, haveria uma economia de aproximadamente US\$13.120,00/ano somente com tubos de grafite. A Tabela 11 mostra a economia proporcionada em tubos de grafite consumidos para realizar 10000 determinações utilizando-se o método proposto. 
Tabela 11. Custos analíticos para 10000 determinações utilizando modificador permanente W+Rh e co-injeção de Rh (THGA end-capped-Perkin-Elmer) versus modificação convencional $\mathrm{Pd}+\mathrm{Mg}$, tubo de grafite modelo Universal

\begin{tabular}{|c|c|c|}
\hline \multirow[b]{2}{*}{ Modificador } & \multicolumn{2}{|c|}{ Características } \\
\hline & W-Rh ${ }^{(a)}$ & $\mathrm{Pd}+\mathrm{Mg}\left(\mathrm{NO}_{3}\right)_{2}{ }^{(b)}$ \\
\hline Custo do atomizador / tipo & $\begin{array}{c}\text { US\$ } 60 \text { - Tubo Universal } \\
\text { (Varian) }\end{array}$ & $\begin{array}{l}\text { US\$ } 100 \text { - (THGA end- } \\
\text { capped) (Perkin-Elmer) }\end{array}$ \\
\hline $\begin{array}{l}\text { Tempo de vida útil do atomizador I } \\
\text { queimas }\end{array}$ & $n=850$ & $n=250$ \\
\hline Número de determinações & 10000 & 10000 \\
\hline $\begin{array}{l}\text { Número de tubos de grafite } \\
\text { consumidos }\end{array}$ & 12 & 40 \\
\hline Custo com tubos de grafite & US\$ 720,00 & US $\$ 4000,00$ \\
\hline $\begin{array}{llll}\text { Economia usando o modificador } \\
\text { permanente } \mathrm{W}+\mathrm{Rh} & \text { ou } \\
\text { modificação } & \text { convencional } & \text { de } \\
\mathrm{Pd}+\mathrm{Mg} & & & \end{array}$ & US\$ $3.280,00$ & \\
\hline
\end{tabular}

(a) Solução de açúcar injetada diretamente no tubo de grafite Universal e co-injeção de $5 \mu \mathrm{g}$ de Rh em solução.

(b) Solução de açúcar injetada diretamente no tubo de grafite e co-injeção de $5 \mu \mathrm{g}$ de $\mathrm{Pd}+3 \mu \mathrm{g}$ Mg. 


\subsection{Comparação do método proposto para determinação direta de chumbo em açúcar}

A demanda de análises de metais em amostras de açúcar tem crescido nos últimos anos, devido, principalmente, a abertura e exigências de novos mercados para exportação (e.g. Rússia, Índia, Senegal, Egito). Contudo, não há disponibilidade de materiais de referência certificados para validação de novos métodos analíticos.

O método proposto neste trabalho para determinação direta de chumbo, utilizando o modificador permanente $W+R h \quad e$ co-injeção de $\mathrm{Rh}$ e a modificação convencional com $\mathrm{Pd}+\mathrm{Mg}$, foi comparado com o método proposto por Lima et al. (1998) em 12 amostras de açúcar de diferentes procedências. Soluções $8 \% \mathrm{~m} / \mathrm{v}$ de açúcar foram preparadas transferindo-se $4 \mathrm{~g}$ de açúcar para balão volumétrico de $50 \mathrm{ml}$ e completando-se o volume com solução $5 \mu \mathrm{g} \mathrm{I}^{-1} \mathrm{~Pb}$ em $0,2 \% \mathrm{v} / \mathrm{v} \mathrm{HNO}_{3}$.

Utilizou-se um espectrômetro de absorção atômica com forno de grafite de aquecimento transversal com corretor de fundo por efeito Zeeman longitudinal modelo Perkin Elmer SIMAA 6000 do Instituto de Química da Universidade Estadual Paulista - Campus de Araraquara. Em ambos os métodos, obtiveram-se recuperações quantitativas para a massa (250 ng) adicionada de chumbo nas soluções $8 \% \mathrm{~m} / \mathrm{v}$ de açúcar com $0,2 \% \mathrm{v} / \mathrm{v} \mathrm{HNO}_{3}$. Contudo a concentração de chumbo nas amostras foi inferior aos limites de detecção. A Tabela 12 mostra os resultados obtidos na comparação de ambos métodos. 
Tabela 12. Comparação dos resultados na determinação direta de chumbo em açúcar com adição de $5 \mu \mathrm{g} \mathrm{I}^{-1} \mathrm{~Pb}$, utilizando superfície grafite revestida com $\mathrm{W}+\mathrm{Rh}{ }^{(\mathrm{a})}$, modificação convencional de $\mathrm{Pd}+\mathrm{Mg}^{(\mathrm{b})}$ e método proposto por Lima et al. $(1998)^{(c)}$

\begin{tabular}{ccccc}
\hline Localidade & Amostra & Método $^{(\mathrm{a})}$ & Método $^{(\mathrm{b})}$ & Método $^{(\mathrm{c})}$ \\
\cline { 3 - 5 } & & $\mu \mathrm{gl}^{-1}(\mathrm{n}=3)$ & $\mu \mathrm{g} \mathrm{I}^{-1}(\mathrm{n}=3)$ & $\mu^{-1}(\mathrm{n}=3)$ \\
\hline São Paulo & demerara & $5,1 \pm 0,11$ & $5,0 \pm 0,11$ & $5,1 \pm 0,06$ \\
São Paulo & demerara & $4,9 \pm 0,14$ & $4,9 \pm 0,07$ & $5,0 \pm 0,14$ \\
São Paulo & orgânico & $4,9 \pm 0,07$ & $4,9 \pm 0,07$ & $5,0 \pm 0,14$ \\
São Paulo & refinado & $5,0 \pm 0,14$ & $5,0 \pm 0,14$ & $5,2 \pm 0,07$ \\
São Paulo & cristal & $4,9 \pm 0,13$ & $4,9 \pm 0,07$ & $5,1 \pm 0,14$ \\
São Paulo & cristal & $5,1 \pm 0,14$ & $5,0 \pm 0,11$ & $5,1 \pm 0,14$ \\
São Paulo & cristal & $5,0 \pm 0,14$ & $5,0 \pm 0,14$ & $5,1 \pm 0,06$ \\
São Paulo & cristal & $5,1 \pm 0,14$ & $5,0 \pm 0,07$ & $5,0 \pm 0,11$ \\
São Paulo & cristal & $4,9 \pm 0,07$ & $4,9 \pm 0,07$ & $5,0 \pm 0,14$ \\
Goiás & cristal & $4,9 \pm 0,14$ & $4,9 \pm 0,14$ & $5,1 \pm 0,11$ \\
Minas Gerais & cristal & $4,9 \pm 0,07$ & $4,9 \pm 0,07$ & $4,9 \pm 0,06$ \\
Mato Grosso & cristal & $4,9 \pm 0,14$ & $4,9 \pm 0,11$ & $5,1 \pm 0,14$ \\
do Sul & & & & \\
\hline
\end{tabular}

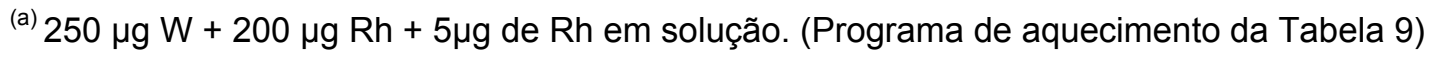

(b) $5 \mu \mathrm{g} \mathrm{Pd}+3 \mu \mathrm{g} \mathrm{Mg.} \mathrm{(Programa} \mathrm{de} \mathrm{aquecimento} \mathrm{da} \mathrm{Tabela} \mathrm{9)}$

${ }^{(c)}$ método proposto por Lima et al. (1998). (Programa de aquecimento da Tabela 5)
} 


\section{CONCLUSÕES}

Neste trabalho avaliou-se o modificador químico permanente W-Rh e o modificador convencional $\mathrm{Pd}+\mathrm{Mg}$ para a determinação de chumbo em açúcar. Com a modificação permanente observou-se a necessidade da co-injeção de Rh na solução de açúcar para estabilizar o chumbo na etapa de pirólise em temperaturas superiores a $600^{\circ} \mathrm{C}$. O modificador permanente de W-Rh permaneceu estável por 250 queimas. Em ambos procedimentos o número médio de queimas obtidos foi de 850. Observou-se que o recobrimento com W-Rh não prolonga a vida útil do forno de grafite universal da Varian, quando comparado com a modificação convencional de $\mathrm{Pd}+\mathrm{Mg}$, mas há forte indicação de que o número da recalibração será menor com plataforma tratada com W+Rh. O limite de detecção do método foi $5 \mathrm{ng} \mathrm{g}^{-1}\left(0,4 \mu \mathrm{g} \mathrm{I}^{-1} \mathrm{~Pb}\right.$ em solução) empregando tubos de grafite com modificação permanente ou convencional. Conclui-se que o procedimento proposto é adequado para determinação de chumbo em açúcar.

Há consistente indicação do prolongamento da vida útil do tubo de grafite (THGA end-capped) revestido termicamente com $250 \mu \mathrm{g} \mathrm{W}$ + $200 \mu \mathrm{g}$ Rh e co-injeção de $5 \mu \mathrm{g}$ Rh, uma vez que foi possível aumentar o número de queimas (> 40\%), quando comparado com a modificação convencional de $\mathrm{Pd}+\mathrm{Mg}$ proposta por Lima et al. (1998) para determinação de chumbo em açúcar. Muito provavelmente este aumento do número de queimas poderá será ultrapassado em futuro próximo. 


\section{REFERÊNCIAS BIBLIOGRÁFICAS}

AGÊNCIA NACIONAL DE VIGILÂNCIA SANITÁRIA - ANVISA. Portaria $\mathrm{n}^{\circ}$ 685, de 27 de agosto de 1998. Brasília, 4p. http://www.anvisa.gov.br/legis/portarias/685 98.htm (10/out.2003).

ALLOWAY, B.L. Heavy metals in soils. 2.ed. London: Blackie Academic e Professional, 1995.

ANDERSON, G.H. Sugars and health: A review. Nutrition Research, v.9, p.1485-1498, 1997.

ARRUDA, M.A.Z.; GALLEGO, M.; VALCÁRCEL, M. Direct analysis of food as solids or slurries by atomic spectrometry. Química Analitica, v.14, p.17-26, 1995.

ASSOCIAÇÃO BRASILEIRA DE NORMAS TÉCNICAS. Determinação de chumbo em açúcar. NBR 9920. Rio de Janeiro: ABNT, 1987. 3p 
BAILY, P.; NORVAL, E.; KILROESMITH, T.A.; SKIKNE, M.I.; ROLLIN, H.B. The application of metal-coated graphite tubes to the determination of trace metals in biological materials. The determination of lead in blood using tungsten-coated graphite tube. Microchemical Journal, v.24, p.107-116, 1979.

BARBOSA JÚNIOR, F. Determinação de bismuto, chumbo, e crômio em amostras de interesse clinico por espectrometria de absorção atômica em forno de grafite com modificação química permanente. São Carlos, 2003. 100p. Tese (Doutorado) - Instituto de Química de São Carlos, Universidade de São Paulo.

BARBOSA JÚNIOR, F. Avaliação de modificadores químicos permanentes em atomizadores metálicos e grafíticos para espectrometria de absorção atômica com atomização eletrotérmica. São Carlos: IQSC/USP, 1999. (Projeto de Pesquisa).

BARBOSA JÚNIOR, F.; LIMA, E.C.; KRUG, F.J. Arsenic determination in soil and sediment slurries by ETAAS using permanent modifier. Analyst, v.125, p.2079-2083, 2000.

BARRERA-BERMEJO, P.; BARCIELA-ALONSO, M.C.; MOREDAPINEIRO, J.; GONZALEZ-SIXTO, C.; BERMEJO-BARRERA, A. Determination of trace metals (As, $\mathrm{Cd}, \mathrm{Hg}$, and $\mathrm{Sn}$ ) in marine sediment slurry samples by electrothermal atomic absorption spectrometry using palladium as a chemical modifier. Spectrochimica Acta, v.51, p.1573-1589, 1996. 
BEATY, R. D.; KERBER, J.D. Concepts, instrumentation and techniques in atomic absorption spectrophotometry. Norwalk: Perkin-Elmer Corporation, 1993.

BECHARA, E.J.H. Chumbo, intoxicação e violência. Jornal do Conselho Regional de Química IV região (SP e MS), n.65, p.8-10, 2004.

BLAKE, C.; BOURQUI, B. Determination of lead and cadmium in food products by graphite furnace atomic absorption spectroscopy. Atomic Spectroscopy, v.19, n.6, 207-213, 1998.

BULSKA, E.; KANDLER, W.; HULANICKI, A. Noble Metals as permanent Modifiers for the determination of mercury by electrothermal atomic absorption spectrometry. Spectrochimica Acta, v.51B, p.1623-1270, 1996.

BULSKA, E.; PYRZYNSKA, K. Comparison of chemical modifiers for the determination of selenium by electrothermal atomic-absorption spectrometry. Spectrochimica Acta, v.52B, p.1283 -1291, 1997.

BULSKA, E.; JEDRAL, W. Application of palladium-plating and rhodium plating of the graphite-furnace in electrothermal atomic-absorption spectrometry. Journal of Analytical Atomic Spectrometry, v.10, p.49-53, 1995. 
DAKUKAZU, C.S.; FRESCHI, G.P.G.; MORAES, M.; GOMES NETO, J.A. Influência de nitrato de paládio, nitrato de magnésio e nitrato de níquel no comportamento térmico de arsênio em açúcares por espectrometria de absorção atômica em forno de grafite. Eclética Química, v.26, p.143-155, 2001.

DAKUKAZU, C.S.; FRESCHI, G.P.G.; MORAES, M.; NÓBREGA, J.A.; NETO, J.A.G. Direct determination of arsenic in sugar by GFAAS with transversely heated graphite atomizer and longitudinal Zeeman effect background correction. Atomic Spectroscopy, v.2, n.2, p.271-275, 2001.

DA SILVA, J.B.B.; DA SILVA, M.A.M.; CURTIUS, A.J.; WELZ, B. Determination of $\mathrm{Ag}, \mathrm{Pb}$ and $\mathrm{Sn}$ in aqua regia extracts from sediments by electrothermal atomic absorption spectrometry using $\mathrm{Ru}$ as a permanent modifier. Journal of Analytical Atomic Spectrometry, v.14, p.1737-1742, 1999.

DA SILVA, J.B.B.; BERTILIA, M.; GIACOMELLI, O.; SOUZA, I.G; CURTIUS, J. A. Iridium and Rhodium as permanent chemical modifiers for the determination of $\mathrm{Ag}, \mathrm{As}, \mathrm{Bi}, \mathrm{Cd}$, and $\mathrm{Sb}$ by electrothermal atomic absorption spectrometry. Microchemical Journal, v.60, p.249-257, 1979.

DOCEKALOVÁ, H.; DOCEKAL, B.; KOMÁREK, J.; NOVOTNÝ, I. Determination of selenium by electrothermal atomic absorption spectrometry - part 1: Chemical modifiers. Journal of Analytical Atomic Spectrometry, v.6, p.661-668, 1991. 
EDIGER, R.D. Atomic absorption analysis with the graphite furnace using matrix modification. Atomic Absorption Newsletter, v.14, n.5, p.127-130, 1975.

FAO/WHO CODEX ALIMENTARIUS COMMISSION. Codex alimentarius. Rome: FAO; WHO, 1995. CX/FAC 96/17.

FRESCHI, G.P.G.; DAKUZAKU, C.S.; MORAES, M.; NÓBREGA NETO, J.A.G. Simultaneous determination of cadmium and lead in wine by electrothermal atomic spectrometry. Spectrochimica Acta, v.56B, p.1987-1993, 2001.

GOMES NETO, J.A.; ZARA, L.F.; ROCHA, J.C.; SANTOS, A.; DAKUZAKU, C.S.; NÓBREGA, J.A. Determination of mercury in agroindustrial samples by flow-injection cold vapor atomic absorption spectrometry using ion exchange and reductive elution. Talanta, v.51, p.587-594, 2000.

HUIJBREGTS, A.W.M.; HIBBERT, D.; PHILLIPSON, R.T.; SCHIWECK, H.; STEINLE, G. Collaborative study on the determination of trace elements in dried sugar beet pulp and molasses. Part IV. Arsenic. International Sugar Journal, v.87, p.164-167, 1985.

INTERNATIONAL COMMISSION FOR UNIFORM METHODS OF SUGAR ANALYSIS - ICUMSA. The determination of lead in sugars and syrups by a GFAAS Method Official. Method GS2/3-24. New York, 1998. 
INTERNATIONAL COMMISSION FOR UNIFORM METHODS OF SUGAR ANALYSIS - ICUMSA. The determination of arsenic, cadmium, copper and iron in white sugar by atomic absorption spectroscopy. Method GS2/3-23. London, 2001.

INTERNATIONAL UNION OF PURE AND APPLIED CHEMISTRY - IUPAC. Nomenclature, symbols, units and their usage in spectrochemical analysis - II. Data interpretation Analytical Chemistry Division. Spectrochimica Acta v.33 p.241, 245, 1978.

KOPYSC, E.; BULSKA, E.; WENNRICH, R. On the use of noble metals modifiers for simultaneous determination of $\mathrm{As}, \mathrm{Sb}$, and $\mathrm{Se}$ by electrothermal atomic absorption spectrometry. Spectrochimica Acta, v.58, p.1515-1523, 2002.

LAJOLO, F.M.; MENEZES, E.W. Tabela brasileira de composição de alimentos. São Paulo: FCF/USP, 2001. http://www.fcf.usp.br/tabela/Danemenu.htm. (06 ago. 2002).

LEBLEBICI, J.; VOLKAN, M. Sample preparation for arsenic, copper, iron, and lead determination in sugar. Journal of Agriculture and Food Chemistry, v.46, p.173-177, 1998.

LENDINEZ, E.; LOPEZ, M.C.; CABRERA, C.; LORENZO, M.L. Determination of chromium in wine and other alcoholic beverages consumed in Spain by electrothermal atomic absorption spectrometry. Journal of AOAC International, v.8, n.1041, p.1043-1047, 1998. 
LIMA, E.C. Desenvolvimento de métodos para determinação de metais de interesse agropecuário e industrial por espectrometria de absorção atômica com atomização eletrotérmica. São Carlos, 1998. 100p. Tese (Doutorado) - Centro de Ciências Exatas e de Tecnologia, Universidade Federal de São Carlos.

LIMA, E.C.; KRUG, F.J.; JACKSON, K.W. Evaluation of tungstenrhodium coating on an integrated platform as a permanent chemical modifier for cadmium, lead and selenium determination by electrothermal atomic absorption spectrometry. Spectrochimica Acta, v.53B, p.1791-1804, 1998.

LIMA, E.C.; BARBOSA JÚNIOR, F.; KRUG, F.J.; ARRUDA, M.A.Z. Direct determination of lead in sweet fruit - flavored powder drinks by electrothermal atomic absorption spectrometry. Spectrochimica Acta, v.53B, p.601-611, 1998.

LIMA, E.C.; BARBOSA JÚNIOR, F.; KRUG, F.J.; GUAITA, U. Tungstenrhodium permanent chemical modifier for lead determination in digest of biological materials and sediments by electrothermal atomic absorption spectrometry. Journal of Analytical Atomic Spectrometry, v.14, p.1601-1605, 1999.

LIMA, E.C.; BARBOSA JÚNIOR, F.; KRUG, F.J. Tungsten-rhodium permanent chemical modifier for lead determination in sediment slurries by electrothermal atomic absorption spectrometry. Journal of Analytical Atomic Spectrometry, v.14, p.1913-1918, 1999. 
LIMA, E.C.; BARBOSA JÚNIOR, F.; KRUG, F.J. The use of tungstenrhodium permanent chemical modifier for cadmium determination in decomposed samples of biological materials and sediments by electrothermal atomic absorption spectrometry. Analytical Chimica Acta, v.409, p.267-274, 2000.

LIMA, E.C.; BRASIL, J.L.; VAGHETTTI, J.C.P. Evaluation of different permanent modifiers for the determination of arsenic in environmental samples by electrothermal atomic absorption spectrometry. Talanta, v.60, p.103-113, 2003.

MAGALHÃES, C.G.; LELIS, K.L.A.; ROCHA, C.A.; DA SILVA, J.B.B. Direct determination of aluminium in serum and urine by electrothermal atomic absorption spectrometry using ruthenium as permanent modifier. Analytica Chimica Acta, v.464, p.323-330, 2002.

MANNING, D.C.; SLAVIN, W. The determination of traces elements in natural waters using the stabilized temperature platform furnace. Applied Spectroscopy, v.37, n.37, p.1-11, 1983.

MATOUSEK, J.P.; POWELL H.K.J. Coupled in situ eletrodepositionelectrothermal atomic absorption spectrometry: a new approach in quantitative matrix free analysis. Spectrochimica Acta, v.50B, p.857-872, 1995. 
MEI, L.I.; ZHE-MING, N.I.; ZHU, R. Determination of selenium in biological tissue samples rich in phosphorus using electrothermal atomization with Zeeman-effect background correction and $\left(\mathrm{NH}_{4}\right)_{3} \mathrm{RhCl}_{6}+$ citric acid as a mixed chemical modifier. Spectrochimica Acta, v.53B, p.1381-1389, 1998.

MEERAVALI, N.N.; KUMAR, S.J. Zirconium-iridium coating as a permanent modifier for determination of tin in stream sediment, oyster tissue and total diet slurries by electrothermal atomic absorption spectrometry. Journal of Analytical Atomic Spectrometry, v.17, p.704-709, 2002.

MILHER-ILHI, N.J.; GREENE, F.E. Direct determination of lead in sugars using graphite atomic absorption spectrometry.

Atomic Spectroscopy, v.14, n.4, p.85-89, 1993.

MILLER-IHLI, N.J. Graphite furnace atomic absorption method for the determination of lead in sugars and syrups. Journal of AOAC International, v.77, n.5, 1288-1292, 1994.

MILLER-IHLI, N.J. Evaluation of a graphite furnace atomic absorption method developed for the determination of lead in sugars. Journal of Agriculture and Food Chemistry, v.43, p.923-927, 1995.

MILLER-IHLI, N.J. Slurry sampling electrothermal atomic absorption spectrometry: results from the second phase of an international collaborative study. Journal of Analytical Atomic Spectrometry, v.12, p.205-212, 1997. 
MOHAMED, A.E. Environmental variations of trace element concentrations in Egyptian cane sugar and soil samples (Edfu factories). Food Chemistry, v.65, p.503-507, 1999.

MORENO, R.G.M.; OLIVEIRA, E.; PEDROTTI, J.J.; OLIVEIRA, P.V. An electrothermical flow-cell for permanent modification of graphite tube with palladium for mercury determination by electrothermal atomic absorption spectrometry. Spectrochimica Acta, v.57B, p.769-778, 2001.

MORRIS, N.M.; CLARKE, M.A.; TRIPP, V.W.; CARPENTER, F.G. Determination of lead, cadmium, and zinc in sugar. Journal of Agriculture and Food Chemistry, v.24, n.1, p.45-47, 1976.

NATIONAL ACADEMY OF SCIENCES. Food chemicals CODEX. 4.ed Washington: Committee on Food Chemicals Codex, Food and Nutrition Board, Institute of Medicine, National Academy of Sciences, 1996 p.400-401, 763-765.

NÓBREGA, J.A.; GÉLINAS, Y.; KRUSHEVSKA, A. Direct determination of major and trace elements in milk by inductively coupled plasma atomic emission and mass spectrometry. Journal of Analytical Atomic Spectrometry, v.12, p.1243-1246, 1997.

ORHAN, A.; TURKER, A.R.; KILIÇ, Z. Direct determination of bismuth, indium and lead in sea water by Zeeman ETAAS using molybdenum containing chemical modifiers. Talanta, v.49, p.135-145, 1999. 
ORTNER, H.M.; BULSKA, E.; ROHR, U.; SCHLEMMER, S.; WEINBRUCH, S.; WELZ, B. Modifiers and coatings in graphite furnace atomic absorption spectrometry - mechanisms of action ( $A$ tutorial review). Spectrochimica Acta, v.57B, p.1835-1853, 2002.

PARSONS, P.J.; QIAO, H.; ALDOUS, K.M.; MILLS, E.; SLAVIN, V. A low-cost tungsten filament atomizer for measuring lead in blood by absorption spectrometry. Spectrochimica Acta, v.50B, p.1475-1480,1995.

PERKIN-ELMER. Analytical methods for atomic absorption spectroscopy. Norwalk, 1982.

QUEIROZ, Z.F.; ROCHA, F.R.P.; KNAPP, G.; KRUG, F.J. Flow system with in-line separation/preconcentration coupled to graphite furnace atomic absorption spectrometry with $\mathrm{W}$-Rh permanent modifier for copper determination in seawater. Analityca Chimica Acta, v.463, p.275-282, 2002.

QUINÁIA, S.P.; NÓBREGA, J.A. Direct determination of chromium in gelatine by graphite furnace atomic absorption spectrophometry. Food Chemistry, v.64, p.429-433, 1999.

QUINÁIA, S.P.; NÓBREGA, J.A. Determinação direta de crômio em açúcar e leite por espectrometria de absorção atômica com atomização eletrotérmica em forno de grafite. Química Nova, v.23, n.2, p.185-190, 2000. 
QIAO, H.; JACKSON, K.W. Mechanism of modification by palladium in graphite furnace atomic absorption spectrometry. Spectrochimica Acta, v.46B, p.1841-1859, 1991.

SANG, S.L.; CHENG, W.C.; SHIUE, H.I.; CHENG, H.T. Direct determination of trace metals in cane juice, sugar and molasses by atomic absorption spectrophotometry. The International Sugar Journal, v.77, p.71-75, 1975.

SANTOS, A. Distribuição de metais no reservatório de captação de água superficial Anhumas Américo Brasiliense SP. São Carlos, 1999. 147p. Dissertação (Mestrado) - Instituto de Química de São Carlos, Universidade de São Paulo.

SANTOS JÚNIOR, D. Moagem criogênica para o preparo de suspensões de alimentos visando à determinação de $\mathrm{Cd}, \mathrm{Cr}$ e $\mathrm{Pb}$ por espectrometria de absorção atômica com atomização eletrotérmica em forno de grafite. São Carlos, 2001. 90p. Dissertação (Mestrado) Departamento de Química, Universidade federal de São Carlos.

SANTOS JÚNIOR, D.; BARBOSA JÚNIOR, F.; SOUZA, S.S.; KRUG, F.J. Cryogenic sample grinding for cupper, and manganese determination in human teeth by slurry sampling GFAAS. Journal of Analytical Atomic Spectrometry, v.18, p.939-945, 2003.

SILVA, D.J. Análise de alimentos (Métodos químicos e biológicos). Viçosa: UFV, 1981. 
SLAVEYKOVA, V.I.; LAMPUGNANI, L.; TSALEV, D.L.; SABBATINI, L.; DEGIGLIO, E. Permanent iridium modifier deposited on tungsten and zirconium-treated platforms in electrothermal atomic absorption spectrometry: Vaporization of bismuth, silver and tellurium. Spectrochimica Acta, v.54, p.455-467, 1999.

SLAVIN, W. Graphite furnace AAS. A source book. Ridgefield: PerkinElmer Corporation, Spectroscopy Division, 1984. 229p.

SLAVIN, W.; MANNING, D.C.; CARNICK, G.R. The stabilized temperature platform furnace. Atomic Spectroscopy, v.2, n.5, p.137-145, 1981.

SOUZA, L.G.; LIMA, L.A.; MISCHAN, M.M. Ocorrência de metais em açúcar cristal. Determinação por espectrofotometria de absorção atômica. Brasil Açucareiro, v.88, p.21-29, 1976.

UNIÃO DA AGROINDÚSTRIA CANAVIEIRA DE SÃO PAULO - UNICA. Tecnologia e gestão. São Paulo. www.única.com.br (06 out. 2002).

VARIAN INC. SCIENTIC INSTRUMENTS. Universal graphite tube with integral platform 10/pk. www.varianinc.com/cgibin/nav?ecat/sci/6310002600\&cid=JPPNPIOFL (08 out. 2003).

VASCONCELOS, Y. Não sobra nem o bagaço. Pesquisa Fapesp, v.77, p.66-70, 2002. 
VIÑAS, P.; CAMPILLO, N.; LÓPEZ-GARCIA, I.; CÓRDOBAHERNÁNDEZ, M. Rapid procedures for cobalt and nickel determination in slurried food samples by electrothermal atomic absorption spectrometry. Atomic Spectroscopy, v.16, p.86-89, 1995.

VINAS, P.; LÓPEZ-GARCIA, I.; LANZÓN, M.; CÓRDOBA-HERNÁNDEZ, M. Direct determination of lead, cadmium, zinc, and copper in honey by electrothermal atomic absorption spectrometry using hydrogen peroxide as a matrix modifier. Journal of Agriculture and Food Chemistry, v45, p.3952-3956, 1997.

VOLYNSKY, A.B.; SEDYKH, E.M. Principal processes in graphite atomizers modified by high-melting carbides. Journal of Analytical Atomic Spectrometry, v.4, p.71-75, 1989.

VOLYNSKY, A.B.; KRIVAN, V.; TIKHOMIROV, S.V. A radiotracer study on effectiveness of platinum metals as chemical modifiers in electrothermal atomic absorption spectrometry: behaviour of selenium in a graphite furnace. Spectrochimica Acta, v.51B, p.1253-1261, 1996.

VOLYNSKY, A.B. Catalytic processes in graphite furnaces for electrothermal atomic absorption spectrometry. Spectrochimica Acta, v.51B, p.1573-1589, 1996. 
VOLYNSKY, A.B. Investigation of the mechanisms of the action of chemical modifier for electrothermal atomic absorption spectrometry: What for and how? Spectrochimica Acta, v.53B, p.139-149, 1998.

VOLYNSKY, A.B. Application of graphite tubes modified with high-melting carbides in electrothermal atomic absorption spectrometry. I. General approach. Spectrochimica Acta, v.53B, p.509-535, 1998.

VOLYNSKY, A.B. Mechanisms of action of platinum group modifiers in electrothermal atomic absorption spectrometry. Spectrochimica Acta, v.55B, p.103-150, 2000.

VOLYNSKY, A.B. Chemical modifiers in modern electrotermal atomic absorption spectrometry. Reviews. Journal of Analytical Chemistry, v.58, n.10, p.905-931, 2003.

WELZ, B. Atomic absorption spectrometry. 2.ed. Weinheim: Verlag Chemie, 1985. 505p.

WELZ, B.; SCHLEMMER, G.; MUDACAVI, J.R. Palladium nitrate Magnesium nitrate modifier for electrothermal atomic spectrometry. Part 5. Performance for the determination of 21 elements. Journal of Analytical Atomic Spectrometry, v.7, p.1257-1271, 1992.

WENDL, W.; MULLER-VOGT. Chemical reactions of lead graphite furnace atomic absorption spectrometry. Journal of Analytical Atomic Spectrometry, v.3, p.63-66, 1988. 
ZANÃO, R.A. Determinação de selênio em sangue por espectrometria de absorção atômica com atomização eletrotérmica utilizando superfície grafítica revestida com W-Rh. Piracicaba, 2001. 59p. Dissertação (Mestrado) - Centro de Energia Nuclear na Agricultura, Universidade de São Paulo.

ZANÃO, R.A.; BARBOSA JUNIOR, F.; SOUZA, S.S.; KRUG, F.J.; ABDALLA, A.L. Direct determination of selenium in whole blood by electrothermal atomic absorption spectrometry using W-Rh - coated platform and co - injection of $\mathrm{Rh}$ as thermal stabilizer. Spectrochimica Acta, v.57B, p.291-301, 2002.

ZHOU, Y.; ZANÃO, R.A.; BARBOSA JUNIOR, F.; PARSONS, P.J.; KRUG, F.J. Investigations of a W-Rh permanent modifier for the determination of $\mathrm{Pb}$ in blood by electrothermal atomic absorption spectrometry. Spectrochimica Acta, v.57B, p.1291-1300, 2002. 